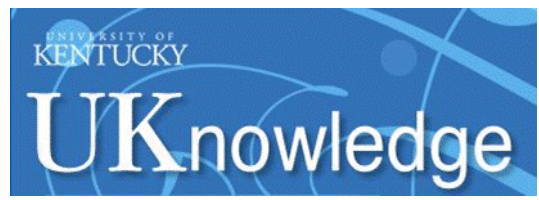

University of Kentucky

UKnowledge

Toxicology and Cancer Biology Faculty

Publications

Toxicology and Cancer Biology

$12-2015$

\title{
Methylseleninic Acid Promotes Antitumour Effects via Nuclear FOXO3a Translocation through Akt Inhibition
}

\author{
Míriam Tarrado-Castellarnau \\ Universitat de Barcelona, Spain \\ Roldán Cortés \\ Universitat de Barcelona, Spain \\ Miriam Zanuy \\ Universitat de Barcelona, Spain \\ Josep Tarragó-Celada \\ Universitat de Barcelona, Spain \\ Ibrahim H. Polat \\ Universitat de Barcelona, Spain
}

See next page for additional authors

Follow this and additional works at: https://uknowledge.uky.edu/toxicology_facpub

Part of the Medical Toxicology Commons

Right click to open a feedback form in a new tab to let us know how this document benefits you.

\section{Repository Citation}

Tarrado-Castellarnau, Míriam; Cortés, Roldán; Zanuy, Miriam; Tarragó-Celada, Josep; Polat, Ibrahim H.; Hill, Richard; Fan, Teresa W-M; Link, Wolfgang; and Cascante, Marta, "Methylseleninic Acid Promotes Antitumour Effects via Nuclear FOXO3a Translocation through Akt Inhibition" (2015). Toxicology and Cancer Biology Faculty Publications. 42.

https://uknowledge.uky.edu/toxicology_facpub/42

This Article is brought to you for free and open access by the Toxicology and Cancer Biology at UKnowledge. It has been accepted for inclusion in Toxicology and Cancer Biology Faculty Publications by an authorized administrator of UKnowledge. For more information, please contact UKnowledge@lsv.uky.edu. 


\section{Methylseleninic Acid Promotes Antitumour Effects via Nuclear FOXO3a Translocation through Akt Inhibition}

Digital Object Identifier (DOI)

http://dx.doi.org/10.1016/j.phrs.2015.09.009

Notes/Citation Information

Published in Pharmacological Research, v. 102, p. 218-234.

(c) Copyright 2015 Elsevier Ltd. All rights reserved.

This manuscript version is made available under the CC-BY-NC-ND 4.0 license

http://creativecommons.org/licenses/by-nc-nd/4.0/

\section{Authors}

Míriam Tarrado-Castellarnau, Roldán Cortés, Miriam Zanuy, Josep Tarragó-Celada, Ibrahim H. Polat, Richard Hill, Teresa W-M Fan, Wolfgang Link, and Marta Cascante 
(C) Copyright 2015 Elsevier Ltd. All rights reserved.

This manuscript version is made available under the CC-BY-NC-ND 4.0 license http://creativecommons.org/licenses/by -nc-nd $/ 4.0 /$ 
Published in final edited form as:

Pharmacol Res. 2015 December ; 102: 218-234. doi:10.1016/j.phrs.2015.09.009.

\title{
Methylseleninic acid promotes antitumour effects via nuclear FOXO3a translocation through Akt inhibition
}

\author{
Míriam Tarrado-Castellarnaua ${ }^{a, b}$, Roldán Cortés ${ }^{a, b}$, Miriam Zanuya,b,1, Josep Tarragó- \\ Celada $^{a, b}$, Ibrahim H. Polat ${ }^{a, b}$, Richard Hillc, ${ }^{c}$, Teresa W. Fan ${ }^{e}$, Wolfgang Link ${ }^{c, d}$, and Marta \\ Cascante ${ }^{a, b},{ }^{*}$ \\ Míriam Tarrado-Castellarnau: mtarrado@ub.edu; Roldán Cortés: roldancortes@ub.edu; Miriam Zanuy: \\ mzanuy@hotmail.com; Josep Tarragó-Celada: joseptarrago11@gmail.com; Ibrahim H. Polat: ihapolat@gmail.com; \\ Richard Hill: drrjhill@gmail.com; Teresa W. Fan: twmfan@gmail.com; Wolfgang Link: walink@ualg.pt \\ aDepartment of Biochemistry and Molecular Biology, Faculty of Biology, Universitat de Barcelona, \\ Av Diagonal 643, Barcelona 08028, Spain \\ bInstitute of Biomedicine of Universitat de Barcelona (IBUB) and CSIC-Associated Unit, \\ Barcelona, Spain \\ 'Centre for Biomedical Research (CBMR), University of Algarve, Campus of Gambelas, Building \\ 8, room 2.22, 8005-139 Faro, Portugal \\ dRegenerative Medicine Program, Department of Biomedical Sciences and Medicine University of \\ Algarve, Campus de Gambelas, 8005-139 Faro, Portugal \\ eDepartment of Toxicology, Markey Cancer Center, and Center for Environmental and Systems \\ Biochemistry (CESB), University of Kentucky, Lexington, KY 40536, USA
}

\begin{abstract}
Selenium supplement has been shown in clinical trials to reduce the risk of different cancers including lung carcinoma. Previous studies reported that the antiproliferative and pro-apoptotic activities of methylseleninic acid (MSA) in cancer cells could be mediated by inhibition of the PI3K pathway. A better understanding of the downstream cellular targets of MSA will provide information on its mechanism of action and will help to optimise its use in combination therapies with PI3K inhibitors. For this study, the effects of MSA on viability, cell cycle, metabolism, apoptosis, protein and mRNA expression, and Reactive Oxygen Species production were analysed in A549 cells. FOXO3a subcellular localisation was examined in A549 cells and in stably transfected human osteosarcoma U2foxRELOC cells. Our results demonstrate that MSA induces FOXO3a nuclear translocation in A549 cells and in U2OS cells that stably express GFP-FOXO3a. Interestingly, sodium selenite, another selenium compound, did not induce any significant effects
\end{abstract}

\footnotetext{
*Corresponding author: martacascante@ub.edu, Telephone: +34 9340215 93, Fax: +34 934021523.

${ }^{1}$ MZ present address: Almirall R\&D Centre, Laureano Miró, 408-410, 08980 Sant Feliu de Llobregat, Barcelona, Spain

Chemical compounds studied in this article

Methylseleninic acid (PubChem CID: 161597); Sodium Selenite (PubChem CID: 24934); Cisplatin (PubChem CID: 441203);

LY294002 (PubChem CID: 3973)

Authors' contributions

MTC, RC, MZ, JTC, IHP, RH and TWF carried out the experiments and performed the statistical analysis. MTC, RC, MZ, WL and MC conceived and designed the study. MTC, RC, MZ, TWF, WL and MC analysed the data, interpreted the results and drafted the manuscript. All authors read and approved the final manuscript.
} 
on FOXO3a translocation despite inducing apoptosis. Single strand break of DNA, disruption of tumour cell metabolic adaptations, decrease in ROS production, and cell cycle arrest in G1 accompanied by induction of apoptosis are late events occurring after $24 \mathrm{~h}$ of MSA treatment in A549 cells. Our findings suggest that FOXO3a is a relevant mediator of the antiproliferative effects of MSA. This new evidence on the mechanistic action of MSA can open new avenues in exploiting its antitumour properties and in the optimal design of novel combination therapies. We present MSA as a promising chemotherapeutic agent with synergistic antiproliferative effects with cisplatin.

\section{Keywords}

Methylseleninic acid; Selenium; FOXO; Akt; PI3K; Cisplatin

\section{Introduction}

Lung cancer is a leading cause of cancer-related mortality and has one of the lowest cure rate worldwide [1]. In early stages of the disease, surgery is the common choice while chemotherapy is the main treatment in advanced lung cancer. The search for new synthetic or natural drugs with low systemic toxicity and high efficiency holds great promise to decrease the morbidity and mortality of cancer. The trace element selenium (Se) in various chemical forms is nutritionally essential for humans but has toxic activity at higher levels [2, 3]. To date, the antioxidant and chemopreventive role of different Se agents as a dietary supplement has not been completely elucidated [4]. Se compounds such as sodium selenite $\left(\mathrm{Na}_{2} \mathrm{SeO}_{3}\right)[5,6]$ and methylseleninic acid $\left(\mathrm{CH}_{3} \mathrm{SeO}_{2} \mathrm{H}\right.$, abbreviated as MSA) have also been studied as potential anticancer agents. MSA is a synthetic precursor of methylselenol $\left(\mathrm{CH}_{3} \mathrm{SeH}\right)$ which induces several cellular, transcriptional and biochemical responses that differ from those induced by selenium forms that are transformed via hydrogen selenide, such as sodium selenite $[7,8]$.

As a constituent of the selenocysteine-containing selenoproteins, selenium has a key role in redox regulation and defence against oxidative stress by greatly enhancing the activity of some antioxidant enzyme systems [9]. Several selenoenzymes, including thioredoxin reductase, iodothyronine deiodinase and glutathione peroxidase, may be associated with cancer development and progression by modulating cell proliferation, transformation, migration and protection against oxidative damage [2]. Selenium deficiency has also been linked to cancer development since it was observed that populations with low selenium intake had greater cancer incidence. Numerous studies and clinical trials have shown that supranutritional doses of individual and mixed selenium compounds inhibit proliferation of cancer cells, induce tumour cell apoptosis, suppress tumour formation and metastasis in animal models and reduce the risk of prostate, lung, breast, and colorectal cancers in humans [9-11]. However, not all selenium compounds have efficacy in chemoprevention, as in a recent large clinical trial (SELECT), selenomethionine was concluded to be ineffective in reducing the risk for prostate cancer development [12]. 
Using a stable isotope-resolved metabolomic (SIRM) approach, Fan and collaborators [13] reported that several metabolites, including lactate, glutathione and glutamate are depleted in A549 lung cancer cells by selenite but not by selenomethionine, suggesting multiple perturbations of the central metabolic networks. Interestingly, the reduction in glycolysis, tricarboxylic acid cycle (TCA) and pentose phosphate pathway (PPP) fluxes observed is opposite to those observed when phosphoinositide-3-kinase (PI3K) pathway is activated [14], pointing to the hypothesis that Se agents target this signalling pathway. Among the selenium compounds with anticancer properties, it has been reported that MSA is a potent inhibitor of the growth and survival of human umbilical vein endothelial cells (HUVECs) and that this antiproliferative effect could be enacted through the PI3K pathway $[15,16]$. Studies with prostate cancer LNCaP, PC-3 (high basal Akt activity) and DU145 cells (low basal Akt activity) have also shown that Akt plays an important role in regulating apoptosis sensitivity to MSA [17]. However, the molecular mechanism of action of MSA is still not fully elucidated.

PI3K/Akt pathway has been shown to be activated in numerous tumours, including lung cancer [18], as it is essential for cell proliferation and survival. Akt is a serine-threonine kinase that is regulated via activation of PI3K. Forkhead box O (FOXO) transcription factors are direct targets of Akt that modulate cellular differentiation, cell cycle, growth, survival, apoptosis, metabolism, DNA repair, resistance to oxidative stress and tumour suppressor pathways [19]. In mammals, FOXO1, FOXO3a and FOXO4 are ubiquitously expressed while FOXO6 is expressed predominantly in neural cells. As transcription factors, FOXO proteins activate or repress the transcription of their target genes through nuclear translocation regulated by post-translational modifications such as phosphorylation, acetylation and ubiquitination [20]. FOXO phosphorylation by Akt impairs its DNA binding activity and promotes its interaction with the chaperone protein 14-3-3, resulting in nuclear exclusion, cytoplasmic accumulation and ubiquitin-proteasome pathway-dependent degradation, thus promoting cell survival. In contrast, FOXO proteins are activated and released from 14-3-3 in the presence of oxidative stress through Jun N-terminal kinase (JNK) signalling [19, 21, 22]. A hallmark of most cancers where the PI3K pathway is hyperactivated (caused by RAS, PTEN or PI3K mutations) is inactivation of FOXO proteins [23]. In contrast, PI3K depletion results in a significant activation of FOXO transcription factors, induction of apoptosis, decrease of cell viability and G1 cell cycle arrest with inhibition of CDK4/6, cyclin D and accumulation of p27 [24]. Therefore, the search for compounds that promote activation and relocalisation of FOXO from the cytoplasm to the nucleus is a promising therapeutic approach for cancer treatment and prevention [25].

In this study, using A549 and U2foxRELOC cells expressing a GFP-FOXO3a fusion protein, we have demonstrated that MSA induces FOXO3a dephosphorylation and nuclear translocation. These findings provide a molecular mechanism to the cytotoxicity, apoptosis, ROS detoxification, cell cycle arrest and metabolic changes observed in A549 cells and implicate FOXO3a as a relevant mediator of MSA antitumour effects.

Moreover, since it has been reported that the antitumour effects of cisplatin are enhanced when it is combined with FOXO nuclear export inhibitors [26-29] and that MSA synergistically sensitised cancer cells in combination with certain chemotherapeutic drugs 
[30, 31], we hypothesised that combined treatment of MSA with cisplatin could be a promising new strategy in cancer therapy.

\section{Methods}

All products were purchased from Sigma-Aldrich Co (St Louis, MO, USA), unless otherwise specified.

\subsection{Chemicals}

MSA was supplied by Dr Fan (University of Kentucky, KY, USA). Sodium selenite was purchased from Sigma-Aldrich. Stock solutions of $10 \mathrm{mM}$ were prepared with Dulbecco's Phosphate Buffer Saline (PBS). The PI3K inhibitor LY294002 was purchased from Calbiochem (San Diego, CA, USA), antibiotic (10000 $\mathrm{U} \mathrm{mL}^{-1}$ penicillin, $10 \mathrm{mg} \mathrm{mL}^{-1}$ streptomycin), PBS, Trypsin EDTA solution C (0.05\% trypsin -0.02\% EDTA) from Biological Industries (Kibbutz Beit Haemet, Israel) and Fetal Bovine Serum (FBS) from Invitrogen (Carlsbad, CA, USA).

\subsection{Cell culture}

Human lung carcinoma A549 cells (ATCC, Manassas, VA, USA) were grown in RPMI-1640 medium with L-glutamine and $10 \mathrm{mM}$ D-Glucose prepared following the manufacturer's instructions. Human osteosarcoma stably transfected U2foxRELOC cells (a gift from Dr Wolfgang Link), human osteosarcoma U2OS cells, human large cell lung cancer NCI-H460 cells, human ovary adenocarcinoma OVCAR3 cells, human embryonic kidney 293 (HEK293) cells and adipocyte-like differentiated 3T3-L1 cells (ATCC) were grown in DMEM with L-glutamine and $25 \mathrm{mM}$ D-Glucose. Human colorectal carcinoma HCT116 cells (ATCC) were cultured in DMEM:HAM F12 (1:1) with L-glutamine and 12.5 mM DGlucose. Human breast adenocarcinoma MCF7 cells (ATCC) were cultured in MEM medium without phenol red (Gibco, Thermo Fisher Scientific Inc., Waltham, MA, USA) containing $10 \mathrm{mM}$ D-glucose, $2 \mathrm{mM}$ L-glutamine, $1 \mathrm{mM}$ pyruvate (Biological Industries), $0.01 \mathrm{mg} \mathrm{mL}^{-1}$ insulin and $1 \%$ non-essential aminoacids (Biological Industries). Media were supplemented with $10 \%$ heat-inactivated FBS, penicillin $\left(50 \mathrm{U} \mathrm{mL}^{-1}\right)$ and streptomycin (50 $\left.\mu \mathrm{g} \mathrm{mL}{ }^{-1}\right)$. U2foxRELOC cells, which express a resistance to Geneticin, were incubated with G418 (Gibco) at $100 \mu \mathrm{g} \mathrm{mL} \mathrm{mL}^{-1}$. 3T3-L1 pre-adipocyte cells were grown in DMEM with 0\% FBS, $10 \%$ NCS and $0.5 \%$ streptomycin/penicillin. Cells were incubated at $37^{\circ} \mathrm{C}$ in a humidified atmosphere with $5 \% \mathrm{CO}_{2}$.

\subsection{T3-L1 differentiation}

Pre-adipocyte 3T3-L1 cells were seeded in 96-well-flat-bottomed microtitre plates. Medium was changed two days after confluence with DMEM containing 0\% NCS, 10\% FBS and induction cocktail $(250 \mu \mathrm{M}$ isobutylmethylxanthine, $1 \mu \mathrm{M}$ dexamethasone and $0.98 \mu \mathrm{M}$ insulin). After $72 \mathrm{~h}$, medium was replaced with 10\% FBS DMEM containing $0.98 \mu \mathrm{M}$ insulin and cells were incubated for $72 \mathrm{~h}$. Then, medium was replaced with $10 \%$ FBS DMEM. Cells were fully differentiated into adipocytes within $48 \mathrm{~h}$ and cell viability assay was performed on them. 


\subsection{Cell growth inhibition}

The assay was performed using a modified method described by Mosmann [32]. Increasing concentrations of the inhibitor were added in sextuplicate in 96-well-flat-bottomed microtitre plates where $2 \times 10^{3}$ A549 cells/well had been seeded $24 \mathrm{~h}$ before. MSA was added to $3 \mathrm{~T} 3-\mathrm{L} 1$ cells once the differentiation process was completed. MSA was depleted after $>24$ $\mathrm{h}$ of treatment, so media was refreshed every day. After 24,48 or 72 hours, $1 \mathrm{mg} \mathrm{mL}^{-1} 3$ (4,5-dimethylthiazol-2-yl)-2,5-diphenyltetrazolium bromide (MTT) in PBS was added at a final concentration of $0.5 \mathrm{mg} \mathrm{mL}^{-1}$. After 1 hour, supernatant was removed and the formazan product was dissolved in $100 \mu \mathrm{L}$ of dimethyl sulfoxide (DMSO). The absorbance was measured on an ELISA plate reader (Tecan Sunrise MR20-301, TECAN, Salzburg, Austria) at $550 \mathrm{~nm}$. Concentrations that caused $50 \%$ of inhibition of cell growth $\left(\mathrm{IC}_{50}\right)$ were calculated using Graphpad Prism 6 software (La Jolla, CA, USA).

\subsection{Cell cycle analysis}

$5 \times 10^{4}$ A549 cells/well were seeded in 6-well plates and treated 24 hours later with MSA for 24,48 and 72 hours. Both adherent and detached cells were collected by centrifugation after trypsinisation, resuspended in $0.5 \mathrm{~mL}$ PBS and added dropwise to $4.5 \mathrm{~mL} 70 \%(\mathrm{v} / \mathrm{v})$ cold ethanol. Cells were stained in PBS containing $50 \mathrm{mg} \mathrm{mL}^{-1}$ propidium iodide (PI), $0.2 \mathrm{mg}$ $\mathrm{mL}^{-1}$ DNAse free RNAse (Roche, Basel, Switzerland) and 0.1\% Triton X-100.

Fluorescence-activated cell sorter (FACS) analysis was carried out at $488 \mathrm{~nm}$ in an Epics XL flow cytometer (Coulter Corporation, Hialeah, FL, USA). Data of $1 \times 10^{4}$ cells were collected and analysed using Multicycle program (Phoenix Flow Systems, San Diego, CA, USA). All experiments were performed three times with three replicates per experiment.

\subsection{Apoptosis assay}

Cells were seeded and treated as described in the cell cycle analysis assay. After centrifugation, cells were washed and resuspended in binding buffer (10 mM Hepes pH 7.4, $140 \mathrm{mM}$ sodium chloride, $2.5 \mathrm{mM}$ calcium chloride). Annexin V coupled with fluorescein isothiocyanate (FITC) was added according to the Annexin V-FITC kit (Bender System MedSystem, Viena, Austria). Following $30 \mathrm{~min}$ of incubation at room temperature in darkness, PI was added at $20 \mu \mathrm{g} \mathrm{mL}{ }^{-1} 1 \mathrm{~min}$ before FACS analysis. Experiments were performed in triplicate and repeated three independent times. Data from $2 \times 10^{4}$ cells were collected and analysed in each experiment.

Apoptosis was also assessed using the membrane-permeable fluorescent dye bisbenzimide Hoechst. After $24 \mathrm{~h}$ in the absence or presence of ${ }^{72} \mathrm{hC}_{50}$ MSA, cells were harvested by mild trypsinisation, collected by centrifugation and fixed with $3.7 \%$ paraformaldehyde for 10 minutes at $-20^{\circ} \mathrm{C}$. Cells were washed with PBS, $0.5 \%$ Triton X-100 was added for 5 min at $4^{\circ} \mathrm{C}$ and cells were stained with $50 \mathrm{ng} \mathrm{mL}^{-1}$ Hoechst 33342 dye for 15 min before placing them onto slides and mounting the coverslips with Mowiol 4-88. Chromatin condensation was visualised by fluorescence microscopy.

\subsection{Single Cell Gel Electrophoresis (SCGE)}

$3 \times 10^{4}$ A549 cells/well were seeded in 6-well plates and treated the next day with ${ }^{72 \mathrm{~h}} \mathrm{IC}_{50}$ MSA, hydrogen peroxide $100 \mu \mathrm{M}$ (positive control) and vehicle (negative control). After 24, 
the comet assay was carried out according to Tice et al. [33]. Briefly, $6 \times 10^{5}$ cells $\mathrm{mL}^{-1}$ were mixed with $140 \mu \mathrm{L}$ of $1 \%$ low-melting-point agarose and $70 \mu \mathrm{L}$ were spread onto pre-coated microscope slides (1\% of normal-melting-point agarose). Glass cover slips (Menzel-Glaser, Braunschweig, Germany) were placed on the gels, which were allowed to set at $4^{\circ} \mathrm{C}$. Then, cover slips were removed and cells embedded in agarose were lysed for 1 hour by immersion in $2.5 \mathrm{M} \mathrm{NaCl}, 100 \mathrm{mM} \mathrm{Na} 2$-EDTA, $10 \mathrm{mM}$ Trizma-HCl (pH 10) and $1 \%$ Triton $\mathrm{X}-100$ at $4^{\circ} \mathrm{C}$. The slides were placed on a horizontal gel electrophoresis tank and the DNA was allowed to unwind for $40 \mathrm{~min}$ in freshly prepared alkaline electrophoresis buffer (300 $\mathrm{mM} \mathrm{NaOH}$ and $1 \mathrm{mM} \mathrm{Na} 2$-EDTA, $\mathrm{pH}>13$ ). Electrophoresis was carried out in the same buffer for $30 \mathrm{~min}$ at $25 \mathrm{~V}$ in an ice bath condition. The slides were rinsed $3 \times 5 \mathrm{~min}$ with 400 $\mathrm{mM}$ Trizma ( $\mathrm{pH}$ 7.5) to neutralise the excess alkali, washed in water (10 minutes), stained with $25 \mu \mathrm{L}$ of 4,6-Diamidino-2-phenylindole (DAPI) (Invitrogen) and covered with a cover. DAPI stained nuclei were evaluated with a Nikon Eclipse TE 300 fluorescence microscope (Nikon, Tokyo, Japan). A total of 100 comets on each gel were visually scored and classified as belonging to one of five classes according to the tail intensity. Each comet class was given a value between 0 (undamaged) and 4 (maximum damage). Total score was calculated by the following equation: (percentage of cells in class $0 \times 0)+($ percentage of cells in class $1 \times 1)+$ (percentage of cells in class $2 \times 2)+($ percentage of cells in class $3 \times 3)+($ percentage of cells in class $4 \times 4)$. Consequently, the total score was in the range from 0 to 400 . Experiments were performed in triplicate.

\section{8. $\left[\mathrm{U}-{ }^{13} \mathrm{C}\right]$-glucose tracer experiments}

A549 cells were seeded in $10 \mathrm{~cm}$ plates and grown in the RPMI medium as described above for 24-36 h before the medium was changed to the RPMI medium with dialysed FBS and $\left[\mathrm{U}_{-}{ }^{13} \mathrm{C}\right]$-glucose, and in the absence (Control) or presence of $5 \mu \mathrm{M}$ MSA. Cells in the tracer medium were grown for another 24 hours before harvest by trypsinisation, followed by 2 washes in excess cold PBS to remove medium components. The final cell pellet obtained from spin at $1700 \mathrm{~g}, 4^{\circ} \mathrm{C}$ for $5 \mathrm{~min}$ was flash-frozen in liquid $\mathrm{N}_{2}$ before extraction with icecold 10\% trichloroacetic acid, as described previously [34]. The polar extracts were aliquoted and lyophilised for analysis by GC-MS and $1 \mathrm{D}{ }^{13} \mathrm{C}$-edited HSQC NMR at $14.1 \mathrm{~T}$, $20^{\circ} \mathrm{C}$ using a $5 \mathrm{~mm} \mathrm{HCN}$ triple resonance cold probe (Agilent Technologies, Santa Clara, CA). For GC-MS analysis, the extracts were derivatised in MTBSTFA before analysis, and for NMR analysis, the extracts were dissolved in $100 \% \mathrm{D}_{2} \mathrm{O}$, as described previously [35].

\subsection{A549 transient transfection with FOXO3a-GFP reporter plasmid}

A549 cells were grown on the surface of cover slips (Menzel-Glaser, Braunschweig, Germany) placed in 6-well plates. When confluence reached $80 \%$, cells were transiently transfected with a previously incubated (30 min) mix containing $2 \mu \mathrm{g}$ of the GFP-FOXO3a reporter plasmid and $2 \mu \mathrm{L}$ of $\mathrm{X}$-tremeGENE HP reagent (Roche) in $200 \mu \mathrm{L}$ medium.

\subsection{FOXO translocation assay}

24 hours after seeding U2foxRELOC cells in 6-well plates containing cover slips or 21 hours after transfection in the case of A549 cells, media were replaced with media containing MSA, sodium selenite, LY294002 $20 \mu \mathrm{M}$ (positive control) or vehicle (negative control). After 6 hours of incubation, media were replaced with fresh media containing $1 \mu \mathrm{M}$ 
CellTracker Red (Invitrogen) and incubated for 10 minutes. Then, media were removed and the cover slips containing the cells were washed $3 \times 5$ min with PBS, fixed with paraformaldehyde for 15 minutes and washed again $3 \times 5$ min with PBS containing $20 \mathrm{mM}$ glycine. The cover slips were then mounted on slides using $20 \mu \mathrm{L}$ ProLong Gold (Invitrogen). After $16 \mathrm{~h}$, the slides were visualised in a TCS SPE Leica confocal microscope (Leica Microsystems, Wetzlar, Germany) and the intensity of the GFP fluorescence in nuclei and cytoplasm was measured from a minimum of 50 random cells per condition using ImageJ software (public domain National Institutes of Health, USA, http://rsbweb.nih.gov/ $\mathrm{ij} /)$.

\subsection{Time course relocalisation assay and data analysis}

The U2foxRELOC-based assay was performed as described previously [36]. All liquid handling for compound treatment, washing, fixing and staining steps was performed by a robotic workstation [37]. Briefly, $1 \times 10^{5}$ cells $\mathrm{mL}^{-1}$ were seeded in black-walled clearbottomed 96-well microplates (BD Biosciences, San Jose, CA, USA) in a final volume of $200 \mu \mathrm{L} /$ well using a multidrop automatic dispenser. After $12 \mathrm{~h}$, cells were treated with $5 \mu \mathrm{M}$ MSA for 1.5, 3, 6, 11 or 24 hours and $10 \mu \mathrm{M}$ LY294002 (positive control) and vehicle (negative control) for 1.5 hours. Cells were washed with PBS, fixed in paraformaldehyde, washed again and stained with DAPI for $20 \mathrm{~min}$ at room temperature to define the nucleus. Assay plates were read on the BD Pathway 855 Bioimager (BD Biosciences) equipped with a 488/10 nm EGFP excitation filter, a 380/10 nm DAPI excitation filter, a 515 LP nm EGFP emission filter and a $435 \mathrm{LP}$ nm DAPI emission filter. Images were acquired in the DAPI and GFP channels of each well by using 20Q dry objective. Data was exported from the BD Pathway Bioimager as text files and imported into the data analysis software BD Image Data Explorer (BD Biosciences) for processing. Cells presenting nuclear accumulation of the fluorescent reporter above $60 \%$ of the signal obtained from wells treated with $10 \mu \mathrm{M}$ LY294002 were considered as hits.

\subsection{Total protein extraction}

$3 \times 10^{5}$ A549 cells per well were seeded in 6-well plates and treated the next day with MSA, sodium selenite, LY294002 or vehicle at the specified concentrations for 6 and 24 hours. At the end of the treatment, cells were washed twice with ice-cold PBS, incubated for $30 \mathrm{~min}$ on ice in lysis buffer containing $20 \mathrm{mM}$ Trizma Base (pH 7.5), $1 \mathrm{mM}$ dithriothreitol, $1 \mathrm{mM}$ EDTA, $0.0002 \%$ Triton X-100, $0.5 \mathrm{mM}$ sodium deoxycholate, $0.4 \mathrm{mM}$ PMSF, $1 \%$ protease inhibitor cocktail and 1\% phosphatase inhibitor cocktail (Thermo Scientific, Thermo Fisher Scientific Inc., Waltham, MA, USA). Cells were scraped, sonicated and centrifuged at 16 $000 \mathrm{~g}$ for $20 \mathrm{~min}$ at $4{ }^{\circ} \mathrm{C}$. Supernatants were recovered and the protein content was quantified by the bicinchoninic acid (BCA) kit (Pierce Biotechnology, Rockford, IL, USA).

\subsection{Cytosolic and nuclear protein extracts}

A549 cells were cultured and treated as described in Total protein extraction section. In this case, cells were incubated for 10 min on ice with hypotonic buffer containing $20 \mathrm{mM}$ HEPES (pH 7.6), $10 \mathrm{mM} \mathrm{NaCl}, 1.5 \mathrm{mM} \mathrm{MgCl} 2,0.2 \mathrm{mM}$ EDTA, $20 \%$ (v/v) glycerol, $0.1 \%$ (v/v) Triton X-100, $1 \%$ protease inhibitor cocktail and $1 \%$ phosphatase inhibitor cocktail. Cells were scraped and pipetted into cooled eppendorf tubes and then centrifuged at 1000 
rpm in a swinging-bucket centrifuge at $4^{\circ} \mathrm{C}$. Supernatant was the cytoplasmic extract and the pellet contained the nuclei. To extract the nuclear proteins, the pellet was resuspended in five times its volume with hypertonic buffer (hypotonic buffer adding $500 \mathrm{mM} \mathrm{NaCl}$ ), rocked for one hour at $4^{\circ} \mathrm{C}$ and spinned at maximum speed at $4^{\circ} \mathrm{C}$ for $5 \mathrm{~min}$. The nuclear extract was the supernatant. Both cytosolic and nuclear extracts were assayed for protein concentration using the BCA kit.

\subsection{Western blot analysis}

An equal volume of protein was size-separated by electrophoresis on SDS-polyacrylamide gels and electroblotted onto polyvinylidene fluoride transfer membranes (PVDF) (Bio-Rad Laboratories, Hercules, CA, USA). After $1 \mathrm{~h}$ of blocking at room temperature with 5\% skim milk in PBS $0.1 \%$ Tween, blots were incubated with the specific primary antibodies overnight at $4{ }^{\circ} \mathrm{C}$. Then, membranes were treated with the appropriate secondary antibody for $1 \mathrm{~h}$ at room temperature. All blots were treated with Immobilon ECL Western Blotting Detection Kit Reagent (EMD Millipore, Billerica, MA, USA) and developed after exposure to an autoradiography film (VWR International, Radnor, PA, USA). The primary antibodies used were Phospho-Akt (\#9271), Akt (\#9272), Phospho-mTOR (\#5536) and procaspase 3 (\#9662) from Cell Signaling (Beverly, MA, USA); FOXO3a (\#06-951) from Upstate (EMD Millipore); Phospho-FOXO3a (sc-101683), Phospho-JNK (sc-6254), FOXM1 (sc-500), Bax (sc-493), CDK4 (sc-260), CDK6 (sc-177), ERK 2 (sc-154) and Lamin B (sc-6217) from Santa Cruz Biotechnology (Santa Cruz, CA, USA); Phospho-PRAS40 (\#44-1100) from BioSource International (Camarillo, CA, USA); PARP (\#556493) and cytochrome c (\#556433) from BD Pharmingen (BD Biosciences); p27 (\#610242) from BD Transduction Laboratories (BD Biosciences) and $\beta$-actin (\#69100) form MP Biomedicals (Santa Ana, CA, USA).

\subsection{FOXO1 gene expression. RNA extraction, quantification, retrotranscription and Quantitative Reverse Transcription-Polymerase Chain Reaction (qRT-PCR)}

RNA was isolated from frozen plates using Trizol reagent (Invitrogen) following the manufacturer's instructions. Briefly, Trizol cell homogenates were mixed with chloroform and centrifuged, obtaining an aqueous phase and an organic phase. In order to precipitate RNA, cold isopropanol was added in the aqueous phase and centrifuged at $12000 \mathrm{~g}$ for 15 min at $4{ }^{\circ} \mathrm{C}$. RNA was purified by several cold $75 \%$ ethanol washes and finally resuspended in RNAse free water. RNA was quantified using a Nanodrop (ND 1000 V3.1.0, Thermo Fisher Scientific Inc.). Reverse transcription was carried out with $1 \mu \mathrm{g}$ RNA at $37^{\circ} \mathrm{C}$ for $1 \mathrm{~h}$ with the following reagents: Buffer 5x (Invitrogen), DTT 0.1 M (Invitrogen), Random

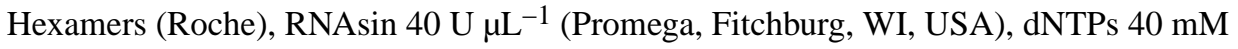

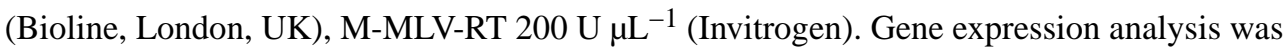
performed on an Applied Biosystems 7500 Real-Time PCR System according to the manufacturer's protocol, using Taqman gene specific sequences (FOXO1: Hs01054576_m1, Applied Biosystems, Thermo Fisher Scientific Inc.). Reactions were performed in $20 \mu \mathrm{L}$ volume, using $9 \mu \mathrm{L}$ of the cDNA mixture and $11 \mu \mathrm{L}$ of the specific Taqman in Master Mix (Applied Biosystems). Real-Time PCR was conducted according to the following parameters: an initial incubation at $50^{\circ} \mathrm{C}$ for $2 \mathrm{~min}$, a denaturalisation at $95^{\circ} \mathrm{C}$ for $10 \mathrm{~min}$, followed by 40 cycles at $95^{\circ} \mathrm{C}$ and $60^{\circ} \mathrm{C}$ for $15 \mathrm{~s}$ and $1 \mathrm{~min}$, respectively. Expression was 
quantified by $\Delta \Delta \mathrm{Ct}$ method using Cyclophilin A (PPIA: Hs99999904_m1, Applied Biosystems) as reference gene.

\subsection{Determination of Intracellular Reactive Oxygen Species (ROS) levels}

A549 cells were grown on 6-well plates to 70\% confluence, washed once with warm PBS, and incubated with $5 \mu \mathrm{M} 2^{\prime}-7^{\prime}$-dichlorodihydrofluorescein diacetate $\left(\mathrm{H}_{2} \mathrm{DCFDA}\right.$, Invitrogen) in PBS supplemented with $5.5 \mathrm{mM}$ glucose. After $30 \mathrm{~min}$ at $37^{\circ} \mathrm{C}$, PBS was replaced with complete culture medium and incubated for another $50 \mathrm{~min}$ at $37^{\circ} \mathrm{C}$. Finally, cells were trypsinised and resuspended thoroughly with $0.4 \mathrm{~mL}$ of PBS, $\mathrm{H}_{2}$ DCFDA $(50 \mu \mathrm{M})$ and PI $(20$ $\left.\mu \mathrm{g} \mathrm{mL}{ }^{-1}\right)$. Intracellular internalised probe reacts with ROS and emits fluorescence when excited at $492 \mathrm{~nm}$. Emitted fluorescence was recorded by flow cytometry at $520 \mathrm{~nm}$ using an Epics XL flow cytometer (Coulter Corporation, Hialeah, FL, USA). Data of DCF fluorescence concentrations from $1 \times 10^{4}$ PI negative cells were collected and analysed using Multicycle program (Phoenix Flow Systems, San Diego, CA, USA).

\subsection{Stable shRNA cell line generation}

U2OS and HEK293 stable FOXO3a knockdown cell lines were generated by Effectene (Qiagen, Hilden, Germany) reagent-mediated transfection with three different FOXO3a shRNA constructs originated from the Netherlands Cancer Institute (NKI) shRNA library [38]. FOXO3a shRNA sequences FOXO3a KD\#1 (GCAGGCCTCATCTCAGAGCTCTCTTGAAGCTCTGAGATGAGGCCTGC), FOXO3a KD\#2 (CTGCGACGGCTGACTGAAATCTCTTGAATTTCAGTCAGCAGTCGCAG) and FOXO3a KD\#3

(CCTGATGGGGGAAANANCTCTCTTGAANCTCTGANATGANGCCTGC) were cloned into pRetroSuper vector (NKI, Amsterdam, Netherlands). Empty pRetroSuper vector was used for control cells (Ctrl). Cells were selected in complete medium containing $1 \mu \mathrm{g} \mathrm{mL}-1$ puromycin.

\subsection{Data analysis and statistical methods}

Experiments were carried out at least in triplicate and repeated three times. To evaluate the effects of combined drug treatments the multiple drug-effect analysis of Chou-Talalay [39] was used with the CompuSyn software (ComboSyn, Inc., Paramus, NJ, USA). MSA interactions with cisplatin and carboplatin were quantified by determining the Combination Index $(\mathrm{CI})$, where $\mathrm{CI}<1, \mathrm{CI}=1$, and $\mathrm{CI}>1$ indicate synergism, additivity, and antagonism, respectively. All data are expressed as mean \pm standard deviation (SD). Statistical analyses were performed using Statgraphics statistical package (Statgraphics Centurion XVI, StatPoint technologies Inc., Warrenton, VA, USA). Control and treatment measurements were compared using Kruskal-Wallis, ANOVA and two-tailed independent sample Student's $\mathrm{t}$ tests. Differences were considered to be significant at $\mathrm{p}<0.05$. 


\section{Results}

\subsection{MSA inhibits cell proliferation and causes G1 arrest in human lung carcinoma A549 cells}

The effect of MSA on human lung carcinoma A549 cell proliferation was examined using the MTT (3-[4,5-dimethylthiazol-2-yl]-2,5-diphenyltetrazolium bromide) colorimetric viability assay. Significant dose-dependent growth inhibition was observed in this cell line after treatment with 10 different concentrations of MSA for 24, 48 and $72 \mathrm{~h}$ (Figure 1A).

The MSA concentrations required for achieving a 50\% growth inhibition on A549 cells after 24,48 and $72 \mathrm{~h}$ of treatment $\left({ }^{24 \mathrm{~h}} \mathrm{IC}_{50},{ }^{48 \mathrm{~h}} \mathrm{IC}_{50}\right.$ and $\left.{ }^{72 \mathrm{~h}} \mathrm{IC}_{50}\right)$ were $2.2 \pm 0.3 \mu \mathrm{M}, 1.6 \pm 0.2$ and $1.3 \pm 0.1 \mu \mathrm{M}$, respectively.

Flow cytometric analyses of cell cycle distribution of A549 cells that had been exposed to ${ }^{72} \mathrm{IC}_{50}$ MSA showed an increase of the G1 population at 24,48 and $72 \mathrm{~h}$ of treatment as compared to control cells (increasing by $41 \%$ at $72 \mathrm{~h}$ ). With the same treatment, a concomitant decrease was also observed in the percentage of cells in the S phase after 24, 48 and $72 \mathrm{~h}$ of treatment with respect to the untreated cells ( $38 \%$ decrease at $72 \mathrm{~h}$ ), suggesting a G0/G1 arrest (Figure 1B). A reduction in the percentage of cells in the G2 phase was also observed at all times.

The interphase cyclin-dependent kinases CDK4 and CDK6 control cell cycle re-entry and progression through G1 phase. In response to mitogenic stimuli, CDK4/6-cyclin D complexes phosphorylate the retinoblastoma (RB) protein family leading to their partial inactivation and relieving the transcriptional repression mediated by the RB-E2F complex [40]. Accordingly, MSA-induced cell cycle arrest could result from negative regulation of CDK4/6-cyclin D complexes. To test this idea, CDK4 and CDK6 protein expression was analysed after incubating A549 cells with $5 \mu \mathrm{M}$ MSA for $6 \mathrm{~h}$. A significant decrease in the protein levels of CDK4/6 was observed in MSA-treated cells (Figure 1C).

To determine whether the concentrations of MSA used in the present study can acidify the media, we measured the $\mathrm{pH}$ values before and after the addition of MSA at 1.3 and $5 \mu \mathrm{M}$ final concentrations. We also assessed the $\mathrm{pH}$ values after the addition of acetic acid, which is a weak acid with an acid dissociation constant $\left(\mathrm{K}_{\mathrm{a}}\right)$ of $1.8 \cdot 10^{-5}$ and a similar molecular structure as MSA. While the addition of acetic acid at $5 \mu \mathrm{M}$ decreased the $\mathrm{pH}$ of the medium by 0.5 units, the same concentration of MSA did not cause any significant effects. Therefore, we conclude that the media were not acidified by the doses of MSA used in this study.

\subsection{MSA induces apoptosis in A549 cells}

Apoptosis was assessed in A549 cells after 24, 48 and $72 \mathrm{~h}$ of treatment with $1.3 \mu \mathrm{M}$ MSA $\left({ }^{72} \mathrm{~h}_{50}\right.$ for growth inhibition). FACS analysis using annexin V-FITC staining and PI accumulation was performed to differentiate non-apoptotic cells (annexin $\mathrm{V}^{-}$and $\mathrm{PI}^{-}$), early apoptotic cells (annexin $\mathrm{V}^{+}$and $\mathrm{PI}^{-}$) and late apoptotic/necrotic cells $\left(\mathrm{PI}^{+}\right)$.

To determine if MSA effects were specific or general to other selenium compounds, sodium selenite was included in our analysis (Figure 2A). MSA treatment for $24 \mathrm{~h}$ caused no 
significant effect on A549 cell apoptosis, while at 48 and $72 \mathrm{~h}$, MSA exposure generated an increase in early apoptotic cells. In contrast, the apoptotic effect of sodium selenite was visible at $24 \mathrm{~h}$ and greatly enhanced at 48 and $72 \mathrm{~h}$ (reaching around $40 \%$ for early apoptotic cells) whereas the percentage of late apoptotic and necrotic cells remained constant at the three time points. Therefore, the extent of apoptosis caused by MSA was much reduced compared to that induced by sodium selenite, which can be due to different mechanisms of apoptosis activation.

Apoptotic cells undergo a series of characteristic morphological changes, such as shrinkage of the cell, chromatin condensation, apoptotic body formation and internucleosomal fragmentation of genomic DNA [41]. In order to evaluate DNA integrity, a single-cell gel electrophoresis was performed (Comet assay). Single strand break of DNA was observed after $24 \mathrm{~h}$ treatment with 1.3 $\mu \mathrm{M}$ MSA (Figure 2B). Total Comet score of treated and untreated cells were 199 and 74, respectively. The presence of apoptotic bodies following 72 h MSA treatment at ${ }^{72} \mathrm{~h}_{50}$ concentration was detected by Hoechst 33342 staining (Figure 2C). Other typical apoptotic features such as rounding, shrinkage, detachment and loss of contact with adjacent cells were observed in MSA-treated cells (Figure 2D) using an inverted phase contrast microscope.

Activation of the caspase pathway plays an important role in apoptosis. Caspases are constitutive cysteine proteases that are normally present as inactive proenzymes. Their enzymatic activity is induced during apoptosis in a self-amplifying cascade. Cleaved upstream caspases (caspases 2, 8, 9 and 10) activate effector caspases (caspases 3,6 and 7) by proteolysis initiating the apoptotic cascade of events [41]. The intrinsic apoptosis pathway involves the release of cytochrome $\mathrm{c}$ into cytosol and the formation of the apoptosome complex by association with APAF-1. This complex activates caspase 9 which in turn cleaves procaspase 3, implicated in the proteolysis of poly (ADP-ribose) polymerase (PARP).

To elucidate the mechanisms involved in MSA or sodium selenite-mediated induction of apoptosis in A549 cells, whole-cell lysates were extracted and Western blot analyses were performed. The effects of LY294002, a known PI3K inhibitor [42], were also assessed. As shown in Figure 2E, incubation with $5 \mu \mathrm{M}$ MSA enhanced the expression of pro-apoptotic Bax and cytosolic cytochrome c, decreased the level of procaspase 3 and caused PARP cleavage. Sodium selenite $5 \mu \mathrm{M}$ treatment induced changes in the same direction but to a significantly lower extent (sodium selenite ${ }^{72} \mathrm{IC}_{50}$ in A549 cells is $5.5 \pm 0.4 \mu \mathrm{M}$, data not shown).

\subsection{MSA blocks glycolysis, TCA cycle and nucleotide biosynthesis}

The effect of MSA on A549 cell metabolism was examined using the Stable IsotopeResolved Metabolomics (SIRM) approach [43-45]. A549 cells were treated with uniformly ${ }^{13} \mathrm{C}$-labeled glucose ([U-13 $\left.\mathrm{C}\right]$-glucose) in the absence (Control) or presence of 5 $\mu \mathrm{M}$ MSA for $24 \mathrm{~h}$. The glucose transformation products were analysed by 1D HSQC NMR and GC-MS, as shown in Figure 3. MSA-treated A549 cells had reduced synthesis of ${ }^{13} \mathrm{C}$ labelled lactate (glycolytic product), malate, aspartate, glutamate, citrate (TCA cycle metabolites), as well as adenine and uracil nucleotides (with the ribose unit derived from the 
PPP), relative to untreated A549 cells. These results suggest that MSA attenuates the activity of glycolysis, TCA cycle, PPP and/or nucleotide biosynthesis.

\subsection{MSA causes nuclear translocation of FOXO3a in U2foxRELOC cells}

Taking into account the arrest of cell cycle (G1), apoptosis induction, the metabolic effects of MSA on A549 cells and their correlation with those described for the PI3K inhibition [14], and the observed effects of MSA on PI3K signalling, we evaluated the effect of MSA on FOXO factors known to be the major transcriptional downstream effecter proteins of the PI3K/Akt signal transduction pathway [46]. As the activity of FOXO factors is mainly regulated by their subcellular localisation [47], we first investigated if MSA induced FOXO nuclear translocation. To this end we used U2foxRELOC cells, a previously established cell system based on U2OS osteosarcoma cells that stably express a GFP-FOXO3a reporter [36, $48,49]$.

In order to select the optimal MSA concentration for analysing its effects on FOXO translocation, the MSA ${ }^{72} \mathrm{hC}_{50}$ in U2foxRELOC cells was determined by incubating the cells with 10 different concentrations of MSA for $72 \mathrm{~h}$ and performing colorimetric viability assay. The values for dose-dependent growth inhibition were similar to the results obtained for A549 cells (Figure 4C). We next analysed the spatio-temporal kinetics of FOXO nuclear translocation upon MSA treatment. We exposed U2foxRELOC cells to $5 \mu$ M MSA for 1.5, $3,6,11$ and 24 hours and determined subcellular localisation of the fluorescent FOXO reporter protein. MSA treatment induced GFP-FOXO3a nuclear translocation from 1.5 to 24 $\mathrm{h}$, reaching a maximum effect between 3 and 6 hours (data not shown).

With the assay conditions optimised, U2foxRELOC cells were treated with 1.3 and $5 \mu \mathrm{M}$ MSA for $6 \mathrm{~h}$ and the subcellular localisation of GFP-FOXO3a was monitored by confocal microscopy. Vehicle was used as a negative control and LY294002 $(20 \mu \mathrm{M})$ as a positive control. As shown in Figure 4A, GFP-FOXO3a was present in the cytosol of untreated cells as well as in the nucleus, whereas in MSA- and LY294002-incubated cells GFP-FOXO3a was localised almost exclusively in the nuclei. The percentage of cells in which GFPFOXO3a nuclear intensity was at least 3.5 times higher than GFP-FOXO3a cytoplasmic intensity was less than 6\% for control cells, more than 95\% for LY294002-treated cells and more than $94 \%$ for MSA-treated cells (at both concentrations) (Figure 4B). To determine whether FOXO3a nuclear translocation was specifically driven by MSA or was a general characteristic of selenium compounds, U2foxRELOC cells were also incubated with sodium selenite at the same concentrations as MSA. The intracellular distribution of GFP-FOXO3a remained unaltered in the presence of sodium selenite (Figure 4A). These results support our hypothesis that MSA specifically induces FOXO3a nuclear translocation.

\subsection{MSA induces GFP-FOXO3a nuclear translocation and increases nuclear FOXO3a in A549 cells}

To further confirm our hypothesis and test if the translocation effect of MSA is also relevant for lung cancer cells, the effect of MSA on FOXO3a in A549 cells was analysed. To this end, we transiently transfected GFP-FOXO into A549 cells and exposed them to MSA. Figures 5A and 5B illustrate the results obtained after $6 \mathrm{~h}$ incubation with $5 \mu \mathrm{M}$ MSA, 20 
$\mu$ M LY294002 or vehicle. MSA induced nuclear accumulation of FOXO3a in A549 cells, resulting in over $90 \%$ of cells exhibiting nuclear fluorescence intensity at least 1.5 times greater than cytoplasmic fluorescence intensity, compared to less than $2.5 \%$ of cells for the control conditions. To confirm the nuclear translocation of endogenous FOXO3a in nontransfected A549 cells in response to MSA treatment, Western blot assays of cells incubated in the same conditions were performed. As shown in Figure 5C, MSA causes an increase in nuclear FOXO3a concentration and a decrease in the levels of cytoplasmic phosphorylated FOXO3a at the Ser253 residue (a known Akt phosphorylation site), consistent with our aforementioned results.

Since it is been described that FOXO1 transcription is stimulated by FOXO3a in a positive feedback loop [50, 51], the effect of MSA on FOXO1 mRNA levels was analysed. Cells were incubated with $5 \mu \mathrm{M}$ MSA for different time periods from $1 \mathrm{~h}$ up to $24 \mathrm{~h}$. Induction of FOXO1 expression was detected from $2 \mathrm{~h}$ to $24 \mathrm{~h}$ and increased in a time-dependent manner (Figure 5D).

To validate the results obtained with confocal microscopy of U2foxRELOC cells treated with MSA and sodium selenite, the levels of active FOXO3a in non-transfected A549 cells were analysed by Western blot. As shown in Figure 6, MSA induced FOXO3a expression while sodium selenite caused its inhibition. To confirm this observation, FOXM1 protein expression was examined, as previous studies have reported that FOXO3a is a negative regulator of FOXM1 at the transcriptional level [52, 53]. In agreement with these observations and further supporting MSA's mode of action through FOXO3a activity, MSA treatment significantly decreased FOXM1 expression while sodium selenite enhanced the level of this transcription factor (Figure 6).

In order to identify the mechanisms involved in FOXO subcellular redistribution, changes in FOXO-regulating signal transduction pathways in response to MSA treatment were studied. It was previously reported that cell cycle arrest induced by FOXO proteins is mediated by enhanced transcription and protein expression of the cyclin-dependent kinase inhibitor p27 $[54,55]$ and reduced protein expression of cyclins D1 and D2 [56]. Both cases result in an impaired capacity of CDK4 and CDK6 to hyperphosphorylate the RB protein family, leading to G1 arrest [40]. Moreover, while FOXO3a has been reported to induce the transcription of p27, PI3K/Akt pathway is known to suppress its expression in order to proceed with cell cycle [57]. To investigate whether MSA-induced G1 cell cycle arrest is associated with Akt and FOXO signalling, p27 and phosphorylation of Akt on Ser 473 status were analysed by Western blot. Six-hour treatment with MSA (at both 1.3 and $5 \mu \mathrm{M}$ ) significantly suppressed Akt phosphorylation without affecting its total protein level (Figure 6). These results suggest that FOXO3a dephosphorylation and nuclear accumulation in response to MSA are mediated by Akt inactivation. The PI3K inhibitor LY294002 showed the same behaviour as MSA while sodium selenite increased Akt phosphorylation in a dosedependent manner. The overactivation of Akt mediated by sodium selenite could account for the depletion in FOXO3a levels observed (Figure 6). PRAS-40, an Akt substrate, followed the same phosphorylation pattern, further supporting our hypothesis (Figure 6). mTOR pathway was downregulated by MSA as phosphorylated mTOR levels were reduced significantly after MSA treatment while sodium selenite activated this signalling pathway by 
increasing P-mTOR level. Dephosphorylation of Akt and FOXO activation preceded the caspase-mediated apoptosis and the transcription of FOXO3a target genes such as p27 (Figure 6). As expected, p27 levels were notably increased after exposure to $5 \mu \mathrm{M}$ MSA and $20 \mu \mathrm{M}$ LY294002 for $24 \mathrm{~h}$, even though p27 level was only slightly enhanced by exposure to $1.3 \mu \mathrm{M}$ MSA. These data corroborate with previous results that showed MSA and sodium selenite inducing distinct biochemical and cellular responses $[7,58,59]$.

\subsection{MSA elicits ROS detoxification}

FOXO proteins have been reported to induce detoxification of reactive oxygen species (ROS) by up-regulating free radical scavenging enzymes, including manganese superoxide dismutase and catalase [25]. FOXO transcription factors regulate two aspects of cellular resistance to stress: repair of damages caused by ROS and detoxification of ROS [19]. Given that MSA causes FOXO3a translocation to the nucleus, we measured ROS levels in A549 cells. The results show that $1.3 \mu \mathrm{M}$ MSA caused a significant decrease in the levels of ROS at 24 and $48 \mathrm{~h}$ (Figure 7). This decrease is consistent with the increased cellular free thiol levels observed by Poerschke et al. [60] after $24 \mathrm{~h}$ MSA incubation. Cells incubated with MSA for $72 \mathrm{~h}$ had similar ROS level to control cells. In contrast, sodium selenite inhibited ROS production at $24 \mathrm{~h}$ but enhanced it at 48 and $72 \mathrm{~h}$.

Previous studies described the role of JNK as a FOXO activator mediating the phosphorylation of 14-3-3 proteins, thus releasing FOXO factors and trigging their nuclear relocalisation [61-63]. As shown in Figure 6, MSA incubation resulted in an increase in PJNK, which is consistent with FOXO activation by Akt dephosphorylation. Sodium selenite enhancement in P-JNK levels could be a consequence of selenite-induced ROS production since JNK cascade can be independently activated by environmental stresses [64].

\subsection{FOXO3a knockdown attenuates MSA effects}

In order to confirm the role of FOXO3a as a mediator of MSA antitumour effects, we stably silenced FOXO3 in two different cell lines using shRNA vectors. We established U2OS and HEK293 cells that stably expressed three different hairpin sequences and validated the efficiency of FOXO3a knockdown by Western blot. The results revealed that FOXO3a KD\#1 construct exhibited the strongest knockdown effect, followed by FOXO3a KD\#2 (Figure 8A). Hence, the U2OS cell lines transfected with these two constructs and the FOXO3a KD\#1 HEK293 cell line were selected to perform the following experiments.

We incubated Ctrl (empty vector) and FOXO3a knockdown cells with $1 \mu \mathrm{M}$ MSA or vehicle (PBS) and measured cell proliferation, cell cycle and apoptosis after $72 \mathrm{~h}$ (Figure 8B-G), and ROS after $48 \mathrm{~h}$ treatment (Figure $8 \mathrm{H}-\mathrm{I}$ ). The results showed that MSA effects were attenuated or even abolished by FOXO3a knockdown. In fact, the observed antiproliferative effect of MSA was significantly reduced after FOXO3a inhibition, while no differences in cell cycle, apoptosis and ROS levels were found between untreated and MSA-treated FOXO3a knockdown cells. These results further confirm that the antitumour response of MSA treatment is mediated by FOXO3a. 


\subsection{MSA as a promising chemotherapeutic agent}

Cisplatin-based therapy is a conventional chemotherapeutic treatment for cancer. However, its clinical efficacy is compromised by acquired resistance and dose-limiting side effects [65]. Consequently, the search for combination therapies and chemosensitising agents to cisplatin is essential for improving its treatment outcome. Given that previous studies reported the enhancement of cisplatin's antitumour effects in combination with FOXO nuclear export inhibitors [26-29], we hypothesised that combined treatment of MSA with cisplatin could be a promising new strategy in cancer therapy.

To quantify the synergy of dose-dependent effect on cell viability, we used the Combination Index (CI) equation of Chou and Talalay [39]. We examined the synergistic effects of MSA and cisplatin in A549, HCT116 (colorectal carcinoma), MCF7 (breast adenocarcinoma) and OVCAR3 (ovary adenocarcinoma) cells which are considered to present cisplatin-resistance, exhibiting IC50 values higher than $10 \mu \mathrm{M}$ [66] (http://www.cancerrxgene.org/translation/ Drug/1005). The combination of MSA and cisplatin treatment in a wide dose range showed a significant synergism in the antiproliferative effects with a $\mathrm{CI}<1$ in each tested cell line (Table 1).

In addition, we studied the synergism of MSA and carboplatin, a derivative of cisplatin commonly used in conventional chemotherapy with similar efficacy, in the same cell lines. Likewise, the combination of MSA and carboplatin treatment in a wide dose range exhibited a synergistic $(\mathrm{CI}<1)$ antiproliferative effect in each tested cell line (Table 2).

Compared with cisplatin or carboplatin single treatments, dosage of these conventional chemotherapeutics could be remarkably reduced in combination therapy with MSA to gain the same inhibitory effect on cell proliferation. Therefore, the synergism observed in HCT116, MCF7, A549 and OVCAR3 cells suggests the combined MSA / cisplatin or carboplatin treatment as an efficient strategy to decrease the chemotherapeutic doses and consequently, mitigate the overall toxicity.

In order to determine if MSA treatment obtained similar growth inhibitory results in other cancer cell lines, the effect of MSA on cell viability in NCI-H460 (large cell lung cancer) and HCT116 (colorectal carcinoma) cell lines was measured. $\mathrm{The}^{72 \mathrm{~h}} \mathrm{IC}_{50}$ values obtained were in the same range as for A549 cells, being $1.7 \pm 0.2 \mu \mathrm{M}$ and $1.9 \pm 0.2 \mu \mathrm{M}$ for NCIH460 and HCT116 cells, respectively (Figure 9A). To investigate if FOXO activation mediated by MSA is a general mechanism and not cell-dependent, HCT116 cell line was used to evaluate FOXO1 mRNA expression, which showed a significant increase in a timedependent manner beginning at $2 \mathrm{~h}$ with $5 \mu \mathrm{M}$ MSA treatment (data not shown).

To test the selective cytotoxicity of MSA for cancer cells, a MTT colorimetric viability assay using a non-tumour non-proliferating cell line was performed. Differentiated 3T3-L1 adipocytes were incubated for $72 \mathrm{~h}$ with 9 different MSA concentrations and the effect on cell proliferation and the ${ }^{72} \mathrm{IC}_{50}$ value were determined (Figure $8 \mathrm{~A}$ ). ${ }^{72 \mathrm{~h}} \mathrm{IC}_{50}$ for MSA in 3T3-L1 cells was three to five times the value for all tumour cell lines that have been studied (Figure 9B), supporting MSA as a promising chemotherapeutic agent with selective antiproliferative effects on cancer cells. 


\section{Discussion}

Selenium is an essential trace element fundamental to human health with pivotal structural and enzymatic functions in selenoproteins. Selenium deficiency has been acknowledged as a contributing factor to a series of distinct pathophysiological conditions, including cancer. Several selenium compounds have shown cancer chemopreventive and chemotherapeutic activities in both animal models and humans [11, 67, 68]. It is important to note that both dose and chemical form of selenium are crucial for the antitumour activity. MSA and sodium selenite are among the forms with high anticarcinogenic activity while selenomethionine used in the SELECT trial was ineffective in cancer prevention in humans $[11,69,70]$.

There are several in vivo studies involving dietary selenium supplementation for cancer therapy and prevention. The evaluation of the effects of different diets containing MSA, sodium selenite or selenomethionine in tumour xenografts in mice has led to the conclusion that MSA exhibits a superior in vivo inhibitory efficacy against human prostate and breast cancers over selenomethionine or sodium selenite [8, 10, 71]. Indeed, dietary supplementation with MSA significantly inhibits xenograft tumour growth and reduces angiogenesis and spontaneous metastasis [8, 10, 71-73]. Importantly, supplementation with MSA does not affect neither the animal body weight nor the food consumption when compared with control diet animals, and histological alterations in organs are not observed, altogether indicating a good tolerance to the used dosage of MSA without adverse side effects $[8,71,72]$. Moreover, MSA supplementation results in less accumulation of selenium both in liver and primary tumour when compared with selenomethionine, while causes no increment in kidney selenium levels relative to controls $[8,10,71]$. These results are consistent with the fact that MSA is efficiently transformed into methylselenol which in turn can be methylated and excreted [74]. Therefore, MSA treatment presents superior in vivo antitumour efficacy with good tolerance results over other selenium derivates $[8,10,71,72]$.

The fact that the molecular mechanism underlying MSA's antitumour properties has not been fully elucidated is a bottle neck in designing combination therapies with MSA. In this study, we described that lung carcinoma A549 cells are very sensitive to MSA treatment, in terms of growth inhibition, cell cycle arrest in G1 phase, attenuated intracellular ROS levels and apoptosis. However, some studies have described selenium derivatives as pro-oxidant products at higher doses than those used in this study [13]. This property could be due to dose dependence: at low concentrations MSA could serve as an antioxidant product, while at higher concentrations it could act as a pro-oxidant compound [69]. The antioxidant function could be mediated via the synthesis of selenocysteine, which is an essential residue of important ROS-detoxifying selenoproteins, such as glutathione peroxidases, thioredoxin reductases and possibly selenoprotein $P$ [75]. Our results suggest distinct redox modulations of the two selenocompounds tested and thus different mechanisms of action. Heightened levels of ROS generated by sodium selenite can cause damage to DNA and mitochondria, leading to apoptosis. Considering these and previous results [6], sodium selenite induces apoptosis through generation of ROS while MSA-mediated apoptosis is regulated by a different molecular pathway like FOXO activation. 
We have also shown that MSA induces FOXO translocation to the nucleus after $1.5 \mathrm{~h}$ of a 5 $\mu \mathrm{M}$ treatment and this localisation is maintained for at least $24 \mathrm{~h}$. In addition, we have demonstrated that FOXO translocation after $1.5 \mathrm{~h}$ is the early event that occurs before the observed molecular and metabolic effects of MSA. Moreover, we have shown that the inhibition of the PI3K pathway through Akt and FOXO3a dephosphorylation could be the molecular mechanism underlying inhibition of cell proliferation, disruption of tumour cell metabolic adaptations, induction of apoptosis, ROS detoxification and cell cycle arrest in A549 cells. Indeed, FOXO3a knockdown attenuated or even abolished the antiproliferative effects of MSA. It is worth noting that although MSA activity is mediated through inhibition of Akt, it does not have an effect on other signalling pathways such as MAPK [7].

FOXO proteins are potentially key targets for new therapeutic strategies for blocking tumourigenesis due to their ability to control cell cycle and promote apoptosis [76]. The tumour suppressor properties of FOXO factors are inhibited mostly by overactivation of their inhibitory signalling, in contrast to other tumour suppressors, whose activities are abrogated by genetic or epigenetic changes. These characteristics call for strategies on rescuing FOXO activity by its reactivation and targeting of its inhibitors [25]. As such, MSA is well-suited to serve as an anticancer agent by inhibiting the PI3K/Akt/mTOR axis and activating JNK signalling pathway, leading to FOXO nuclear relocalisation and restoration of its gene expression. Moreover, combination therapies that target PI3K/Akt pathway and promote nuclear FOXO retention are considered to be a promising approach to treat several tumour types. For example, in recent studies it has been proposed that cytotoxicity of cisplatin in sensitive cells can be enhanced and drug resistance in unresponsive cells reversed by using agents that target the PI3K/Akt/FOXO pathway in combination with cisplatin [26-29]. Our studies support such hypothesis as MSA both synergised with cisplatin and its derivative carboplatin in blocking A549, HCT116, MCF7 and OVCAR3 cell proliferation. Thus, the combination of MSA with either cisplatin or carboplatin could represent a promising new approach to lung cancer treatment in terms of reducing platinum derivatives doses or toxicity as well as drug resistance.

\section{Conclusions}

Our data support a strong antiproliferative action of MSA in the low micromolar range on A549 cells, which is mediated by blocking G1 progression and triggering apoptosis. These MSA effects are associated with the inhibition of the Akt pathway, leading to dephosphorylation of FOXO proteins and their nuclear translocation, which in turn activate the expression of FOXO target genes. The time course data suggest that FOXO dephosphorylation and relocalisation to the nucleus are early events that activate the antiproliferative response of A549 cells to MSA. By targeting the PI3K/Akt/FOXO pathway, MSA could synergise with cisplatin in combination therapy to reduce the commonly observed toxicity and resistance development of cisplatin-based chemotherapy.

\section{Acknowledgments}

This study received financial support from the Ministerio de Ciencia e Innovación, Spain (SAF2011-25726), the Agència de Gestió d'Ajuts Universitaris i de Recerca (AGAUR)-Generalitat de Catalunya (2014SGR1017), the Fundação para a Ciência e a Tecnologia (FCT) Research Center (grant UID/BIM/04773/2013 CBMR 1334) and the 
National Institute of Health, USA (grant numbers 1R01CA118434-01A2 and 1P01CA163223-01A1). We would also like to acknowledge the National Science Foundation, USA (grant number EPS-0447479) for support of the 18.8 Tesla NMR system at the University of Louisville. RH is the recipient of a FCT 2012 research grant (SFRH/BPD/84634/2012) FCT. MC acknowledges the support received through the prize ICREA Academia for excellence in research, funded by ICREA Foundation-Generalitat de Catalunya. The authors thank Ursula Valls and Erika Zodda for their technical support and Dr. Sengodagounder Arumugam for acquiring the NMR data.

\section{Abbreviations}

\begin{tabular}{|c|c|}
\hline MSA & Methylseleninic acid \\
\hline Se & Selenium \\
\hline PPP & Pentose Phosphate Pathway \\
\hline TCA & Tricarboxylic acid \\
\hline ROS & Reactive Oxygen Species \\
\hline $1 D$ HSQC & One Dimension Heteronuclear Single Quantum Coherence \\
\hline${ }^{1} \mathbf{H}-\mathbf{N M R}$ & Proton Nuclear Magnetic Resonance \\
\hline${ }^{72} \mathrm{~h}_{\mathrm{IC}} \mathrm{C}_{\mathbf{5 0}}$ & $\begin{array}{l}\text { Concentration that caused } 50 \% \text { of inhibition of cell growth at } 72 \mathrm{~h} \text { of } \\
\text { treatment }\end{array}$ \\
\hline FOXO & Forkhead box $\mathrm{O}$ \\
\hline FOXM1 & Forkhead box protein M1 \\
\hline Akt & Protein kinase B \\
\hline PI3K & Phosphoinositide-3-kinase \\
\hline mTOR & mammalian Target of Rapamycin \\
\hline CDK & Cyclin-dependent kinase \\
\hline JNK & Jun N-terminal kinase \\
\hline Bax & B-cell lymphoma-2-associated X protein \\
\hline PARP & Poly (ADP-ribose) polymerase \\
\hline PRAS40 & Proline-rich Akt substrate $40 \mathrm{kDa}$ \\
\hline ERK2 & Extracellular signal-regulated kinase 2 \\
\hline
\end{tabular}

\section{References}

1. Ferlay J, Soerjomataram II, Dikshit R, Eser S, Mathers C, Rebelo M, et al. Cancer incidence and mortality worldwide: sources, methods and major patterns in GLOBOCAN 2012. Int J Cancer. 2014

2. Ganther HE. Selenium metabolism, selenoproteins and mechanisms of cancer prevention: complexities with thioredoxin reductase. Carcinogenesis. 1999; 20:1657-66. [PubMed: 10469608]

3. Schrauzer GN. Selenium and selenium-antagonistic elements in nutritional cancer prevention. Critical reviews in biotechnology. 2009; 29:10-7. [PubMed: 19514899]

4. Muecke R, Schomburg L, Buentzel J, Kisters K, Micke O. Selenium or No Selenium- That Is the Question in Tumor Patients: A New Controversy. Integrative Cancer Therapies. 2010; 9:136-41. [PubMed: 20462857] 
5. An JJ, Shi KJ, Wei W, Hua FY, Ci YL, Jiang Q, et al. The ROS/JNK/ATF2 pathway mediates selenite-induced leukemia NB4 cell cycle arrest and apoptosis in vitro and in vivo. Cell Death and Disease. 2013; 4:e973. [PubMed: 24357804]

6. Park SH. Induction of apoptosis and autophagy by sodium selenite in A549 human lung carcinoma cells through generation of reactive oxygen species. Toxicology Letters. 2012; 212:252-61. [PubMed: 22721804]

7. Jiang C, Wang Z, Ganther H, Lü J. Distinct effects of methylseleninic acid versus selenite on apoptosis, cell cycle, and protein kinase pathways in DU145 human prostate cancer cells. Molecular Cancer Therapeutics. 2002; 1:1059-66. [PubMed: 12481429]

8. Li GX, Lee HJ, Wang Z, Hu H, Liao JD, Watts JC, et al. Superior in vivo inhibitory efficacy of methylseleninic acid against human prostate cancer over selenomethionine or selenite. Carcinogenesis. 2008; 29:1005-12. [PubMed: 18310093]

9. Patrick L. Selenium biochemistry and cancer: a review of the literature. Altern Med Rev. 2004; 9:239-58. [PubMed: 15387717]

10. Chen YC, Prabhu KS, Das A, Mastro AM. Dietary selenium supplementation modifies breast tumor growth and metastasis. Int J Cancer. 2013; 133:2054-64. [PubMed: 23613334]

11. Sharma AK, Amin S. Post SELECT: selenium on trial. Future Med Chem. 2013; 5:163-74. [PubMed: 23360141]

12. Lippman SM, Klein EA, Goodman PJ, Lucia MS, Thompson IM, Ford LG, et al. Effect of selenium and vitamin $\mathrm{E}$ on risk of prostate cancer and other cancers: the Selenium and Vitamin E Cancer Prevention Trial (SELECT). JAMA. 2009; 301:39-51. [PubMed: 19066370]

13. Fan TW, Higashi RM, Lane AN. Integrating metabolomics and transcriptomics for probing SE anticancer mechanisms. Drug Metab Rev. 2006; 38:707-32. [PubMed: 17145697]

14. Robey RB, Hay N. Is Akt the "Warburg kinase"?-Akt-energy metabolism interactions and oncogenesis. Seminars in cancer biology. 2009; 19:25-31. [PubMed: 19130886]

15. Wang Z, Jiang C, Ganther H, Lu J. Antimitogenic and proapoptotic activities of methylseleninic acid in vascular endothelial cells and associated effects on PI3K-AKT, ERK, JNK and p38 MAPK signaling. Cancer Res. 2001; 61:7171-8. [PubMed: 11585751]

16. Wu Y. Delineating the mechanism by which selenium deactivates Akt in prostate cancer cells. Molecular Cancer Therapeutics. 2006; 5:246-52. [PubMed: 16505097]

17. Hu H, Jiang C, Li G, Lu J. PKB/AKT and ERK regulation of caspase-mediated apoptosis by methylseleninic acid in LNCaP prostate cancer cells. Carcinogenesis. 2005; 26:1374-81. [PubMed: 15845651]

18. Lin X, Bohle AS, Dohrmann P, Leuschner I, Schulz A, Kremer B, et al. Overexpression of phosphatidylinositol 3-kinase in human lung cancer. Langenbecks Arch Surg. 2001; 386:293-301. [PubMed: 11466572]

19. Greer EL, Brunet A. FOXO transcription factors at the interface between longevity and tumor suppression. Oncogene. 2005; 24:7410-25. [PubMed: 16288288]

20. Lam EW, Brosens JJ, Gomes AR, Koo CY. Forkhead box proteins: tuning forks for transcriptional harmony. Nat Rev Cancer. 2013; 13:482-95. [PubMed: 23792361]

21. Eijkelenboom A, Burgering BMT. FOXOs: signalling integrators for homeostasis maintenance. Nature Reviews Molecular Cell Biology. 2013; 14:83-97. [PubMed: 23325358]

22. Calnan DR, Brunet A. The FoxO code. Oncogene. 2008; 27:2276-88. [PubMed: 18391970]

23. Altomare DA, Testa JR. Perturbations of the AKT signaling pathway in human cancer. Oncogene. 2005; 24:7455-64. [PubMed: 16288292]

24. Reagan-Shaw S. RNA Interference-Mediated Depletion of Phosphoinositide 3-Kinase Activates Forkhead Box Class O Transcription Factors and Induces Cell Cycle Arrest and Apoptosis in Breast Carcinoma Cells. Cancer Research. 2006; 66:1062-9. [PubMed: 16424042]

25. Zhang X, Tang N, Hadden TJ, Rishi AK. Akt, FoxO and regulation of apoptosis. Biochimica et Biophysica Acta (BBA) - Molecular Cell Research. 2011; 1813:1978-86. [PubMed: 21440011]

26. Fernandez de Mattos S, Villalonga P, Clardy J, Lam EW. FOXO3a mediates the cytotoxic effects of cisplatin in colon cancer cells. Mol Cancer Ther. 2008; 7:3237-46. [PubMed: 18852127] 
27. Cortés R, Tarrado-Castellarnau M, Talancón D, López C, Link W, Ruiz D, et al. A novel cyclometallated Pt(ii)-ferrocene complex induces nuclear FOXO3a localization and apoptosis and synergizes with cisplatin to inhibit lung cancer cell proliferation. Metallomics. 2014; 6:622. [PubMed: 24492855]

28. Liu H, Yin J, Wang C, Gu Y, Deng M, He Z. FOXO3a mediates the cytotoxic effects of cisplatin in lung cancer cells. Anticancer Drugs. 2014; 25:898-907. [PubMed: 24814195]

29. Fang L, Wang H, Zhou L, Yu D. FOXO3a reactivation mediates the synergistic cytotoxic effects of rapamycin and cisplatin in oral squamous cell carcinoma cells. Toxicology and Applied Pharmacology. 2011; 251:8-15. [PubMed: 21092744]

30. Yin S, Dong Y, Li J, Fan L, Wang L, Lu J, et al. Methylseleninic acid potentiates multiple types of cancer cells to ABT-737-induced apoptosis by targeting Mcl-1 and Bad. Apoptosis. 2011; 17:38899. [PubMed: 22179721]

31. Hu H, Jiang C, Ip C, Rustum YM, Lu J. Methylseleninic acid potentiates apoptosis induced by chemotherapeutic drugs in androgen-independent prostate cancer cells. Clin Cancer Res. 2005; 11:2379-88. [PubMed: 15788689]

32. Mosmann T. Rapid colorimetric assay for cellular growth and survival: application to proliferation and cytotoxicity assays. J Immunol Methods. 1983; 65:55-63. [PubMed: 6606682]

33. Tice RR, Agurell E, Anderson D, Burlinson B, Hartmann A, Kobayashi H, et al. Single cell gel/ comet assay: guidelines for in vitro and in vivo genetic toxicology testing. Environ Mol Mutagen. 2000; 35:206-21. [PubMed: 10737956]

34. Fan, TW. The Handbook of Metabolomics. New York: 2012. Considerations of Sample Preparation for Metabolomics Investigation; p. 7-27.

35. Lane AN, Fan TW, Higashi RM. Isotopomer-based metabolomic analysis by NMR and mass spectrometry. Methods Cell Biol. 2008; 84:541-88. [PubMed: 17964943]

36. Zanella F, Rosado A, Garcia B, Carnero A, Link W. Chemical genetic analysis of FOXO nuclearcytoplasmic shuttling by using image-based cell screening. Chembiochem. 2008; 9:2229-37. [PubMed: 18756565]

37. Rosado A, Zanella F, Garcia B, Carnero A, Link W. A dual-color fluorescence-based platform to identify selective inhibitors of Akt signaling. PloS one. 2008; 3:e1823. [PubMed: 18350159]

38. Berns K, Hijmans EM, Mullenders J, Brummelkamp TR, Velds A, Heimerikx M, et al. A largescale RNAi screen in human cells identifies new components of the p53 pathway. Nature. 2004; 428:431-7. [PubMed: 15042092]

39. Chou TC, Talalay P. Quantitative analysis of dose-effect relationships: the combined effects of multiple drugs or enzyme inhibitors. Adv Enzyme Regul. 1984; 22:27-55. [PubMed: 6382953]

40. Diaz-Moralli S, Tarrado-Castellarnau M, Miranda A, Cascante M. Targeting Cell Cycle Regulation in Cancer Therapy. Pharmacol Ther. 2013; 138:255-71. [PubMed: 23356980]

41. Saraste A, Pulkki K. Morphologic and biochemical hallmarks of apoptosis. Cardiovasc Res. 2000; 45:528-37. [PubMed: 10728374]

42. Vlahos CJ, Matter WF, Hui KY, Brown RF. A specific inhibitor of phosphatidylinositol 3-kinase, 2-(4-morpholinyl)-8-phenyl-4H-1-benzopyran-4-one (LY294002). The Journal of biological chemistry. 1994; 269:5241-8. [PubMed: 8106507]

43. Fan TW, Lane AN, Higashi RM, Farag MA, Gao H, Bousamra M, et al. Altered regulation of metabolic pathways in human lung cancer discerned by (13)C stable isotope-resolved metabolomics (SIRM). Mol Cancer. 2009; 8:41. [PubMed: 19558692]

44. Fan TW, Lane AN, Higashi RM, Yan J. Stable isotope resolved metabolomics of lung cancer in a SCID mouse model. Metabolomics. 2011; 7:257-69. [PubMed: 21666826]

45. Fan TW, Yuan P, Lane AN, Higashi RM, Wang Y, Hamidi AB, et al. Stable isotope-resolved metabolomic analysis of lithium effects on glial-neuronal metabolism and interactions. Metabolomics. 2010; 6:165-79. [PubMed: 20631920]

46. Zanella F, Link W, Carnero A. Understanding FOXO, new views on old transcription factors. Curr Cancer Drug Targets. 2010; 10:135-46. [PubMed: 20088800]

47. Zanella F, dos Santos NR, Link W. Moving to the Core: Spatiotemporal Analysis of Forkhead Box

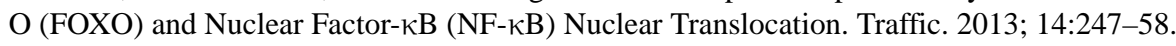
[PubMed: 23231504] 
48. Link W, Oyarzabal J, Serelde BG, Albarran MI, Rabal O, Cebria A, et al. Chemical Interrogation of FOXO3a Nuclear Translocation Identifies Potent and Selective Inhibitors of Phosphoinositide 3Kinases. Journal of Biological Chemistry. 2009; 284:28392-400. [PubMed: 19690175]

49. Zanella F, Rosado A, Garcia B, Carnero A, Link W. Using multiplexed regulation of luciferase activity and GFP translocation to screen for FOXO modulators. BMC Cell Biology. 2009; 10:14. [PubMed: 19243599]

50. Essaghir A, Dif N, Marbehant CY, Coffer PJ, Demoulin JB. The Transcription of FOXO Genes Is Stimulated by FOXO3 and Repressed by Growth Factors. Journal of Biological Chemistry. 2009; 284:10334-42. [PubMed: 19244250]

51. Fang L, Wang H, Zhou L, Yu D. Akt-FOXO3a signaling axis dysregulation in human oral squamous cell carcinoma and potent efficacy of FOXO3a-targeted gene therapy. Oral Oncology. 2011; 47:16-21. [PubMed: 21109483]

52. Yung MM, Chan DW, Liu VW, Yao KM, Ngan HY. Activation of AMPK inhibits cervical cancer cell growth through AKT/FOXO3a/FOXM1 signaling cascade. BMC Cancer. 2013; 13:327. [PubMed: 23819460]

53. Jiang L, Cao XC, Cao JG, Liu F, Quan MF, Sheng XF, et al. Casticin induces ovarian cancer cell apoptosis by repressing FoxM1 through the activation of FOXO3a. Oncol Lett. 2013; 5:1605-10. [PubMed: 23761826]

54. Medema RH, Kops GJPL, Bos JL, Burgering BMT. AFX-like Forkhead transcription factors mediate cell-cycle regulation by Ras and PKB through p27kip1. Nature. 2000; 404:782-7. [PubMed: 10783894]

55. Li CJ, Chang JK, Chou CH, Wang GJ, Ho ML. The PI3K/Akt/FOXO3a/p27Kip1 signaling contributes to anti-inflammatory drug-suppressed proliferation of human osteoblasts. Biochemical Pharmacology. 2010; 79:926-37. [PubMed: 19883628]

56. Schmidt M, Fernandez de Mattos S, van der Horst A, Klompmaker R, Kops GJPL, Lam EWF, et al. Cell Cycle Inhibition by FoxO Forkhead Transcription Factors Involves Downregulation of Cyclin D. Molecular and cellular biology. 2002; 22:7842-52. [PubMed: 12391153]

57. Liang J, Slingerland JM. Multiple Roles of the PI3K/PKB (Akt) Pathway in Cell Cycle Progression. Cell Cycle. 2003; 2:336-42.

58. Li GX, Hu H, Jiang C, Schuster T, Lü J. Differential involvement of reactive oxygen species in apoptosis induced by two classes of selenium compounds in human prostate cancer cells. International Journal of Cancer. 2007; 120:2034-43. [PubMed: 17230520]

59. de Miranda JX, Andrade FD, Conti AD, Dagli ML, Moreno FS, Ong TP. Effects of selenium compounds on proliferation and epigenetic marks of breast cancer cells. J Trace Elem Med Biol. 2014; 28:486-91. [PubMed: 25087768]

60. Poerschke RL, Franklin MR, Moos PJ. Modulation of redox status in human lung cell lines by organoselenocompounds: Selenazolidines, selenomethionine, and methylseleninic acid. Toxicology in Vitro. 2008; 22:1761-7. [PubMed: 18768157]

61. Wang X, Chen WR, Xing D. A pathway from JNK through decreased ERK and Akt activities for FOXO3a nuclear translocation in response to UV irradiation. Journal of Cellular Physiology. 2012; 227:1168-78. [PubMed: 21604264]

62. Sunayama J. JNK antagonizes Akt-mediated survival signals by phosphorylating 14-3-3. The Journal of cell biology. 2005; 170:295-304. [PubMed: 16009721]

63. Sunters A. Paclitaxel-Induced Nuclear Translocation of FOXO3a in Breast Cancer Cells Is Mediated by c-Jun NH2-Terminal Kinase and Akt. Cancer Research. 2006; 66:212-20. [PubMed: 16397234]

64. Zou Y, Niu P, Yang J, Yuan J, Wu T, Chen X. The JNK signaling pathway is involved in sodiumselenite-induced apoptosis mediated by reactive oxygen in HepG2 cells. Cancer Biol Ther. 2008; 7:689-96. [PubMed: 18728404]

65. Dasari S, Tchounwou PB. Cisplatin in cancer therapy: Molecular mechanisms of action. European Journal of Pharmacology. 2014; 740:364-78. [PubMed: 25058905]

66. Garnett MJ, Edelman EJ, Heidorn SJ, Greenman CD, Dastur A, Lau KW, et al. Systematic identification of genomic markers of drug sensitivity in cancer cells. Nature. 2012; 483:570-5. [PubMed: 22460902] 
67. Micke O, Schomburg L, Buentzel J, Kisters K, Muecke R. Selenium in oncology: from chemistry to clinics. Molecules (Basel, Switzerland). 2009; 14:3975-88.

68. Rayman MP. Selenium in cancer prevention: a review of the evidence and mechanism of action. The Proceedings of the Nutrition Society. 2005; 64:527-42. [PubMed: 16313696]

69. Drake EN. Cancer chemoprevention: selenium as a prooxidant, not an antioxidant. Med Hypotheses. 2006; 67:318-22. [PubMed: 16574336]

70. Vinceti M, Dennert G, Crespi CM, Zwahlen M, Brinkman M, Zeegers MP, et al. Selenium for preventing cancer. Cochrane Database Syst Rev. 2014; 3:CD005195. [PubMed: 24683040]

71. Yan L, DeMars LC. Dietary supplementation with methylseleninic acid, but not selenomethionine, reduces spontaneous metastasis of Lewis lung carcinoma in mice. Int J Cancer. 2012; 131:1260-6. [PubMed: 22095442]

72. Zeng H, Wu M. The Inhibitory Efficacy of Methylseleninic Acid Against Colon Cancer Xenografts in C57BL/6 Mice. Nutrition and cancer. 2015:1-8.

73. Wang Z, Hu H, Li G, Lee HJ, Jiang C, Kim SH, et al. Methylseleninic acid inhibits microvascular endothelial G1 cell cycle progression and decreases tumor microvessel density. Int J Cancer. 2008; 122:15-24. [PubMed: 17847021]

74. Ganther HE. Pathways of Selenium Metabolism Including Respiratory Excretory Products. International Journal of Toxicology. 1986; 5:1-5.

75. Steinbrenner H, Sies H. Protection against reactive oxygen species by selenoproteins. Biochimica et biophysica acta. 2009; 1790:1478-85. [PubMed: 19268692]

76. Link W. FOXO proteins as potential targets for anticancer therapy. Current Drug Targets. 2011; 12:1232-4. [PubMed: 21443469] 


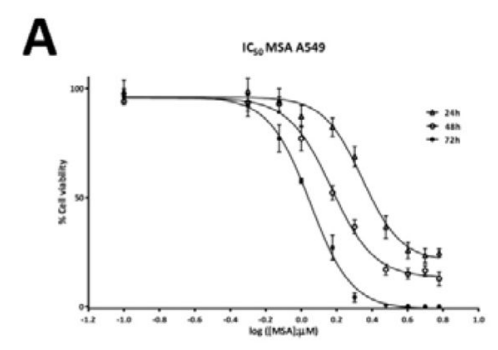

B

$C_{\text {MSA }}$
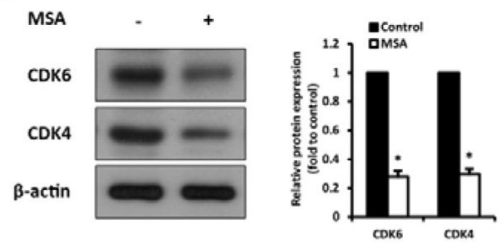

Figure 1. MSA effects on cell viability and cell cycle in A549 cells

A. Growth inhibition of MSA on A549 lung cancer cells after 24, 48 and $72 \mathrm{~h}$ measured by MTT assay. Exponentially growing cells were treated with the indicated concentration of MSA for 24, 48 and $72 \mathrm{~h}$. The assay was carried out using six replicates and repeated three times. Data are represented as mean \pm SD. B. Cell cycle analysis of MSA-treated cells. A549 cells treated for 24, 48, 72 hours with $1.3 \mu$ M MSA presented a G1 arrest. Cell cycle analysis was conducted after propidium iodide staining. Values represent mean $\pm \mathrm{SD}$ and statistically significant differences between treated and control cells at $\mathrm{p}<0.05$ are indicated with an asterisk (*). C. Western blot analysis showed a significant CDK4 and CDK6 inhibition at $6 \mathrm{~h}$ treatment with $5 \mu \mathrm{M}$ MSA. Protein expression levels were quantified using ImageJ software and are expressed as mean band intensity normalised to $\beta$-actin and relative to control condition $(*, p<0.05)$. 

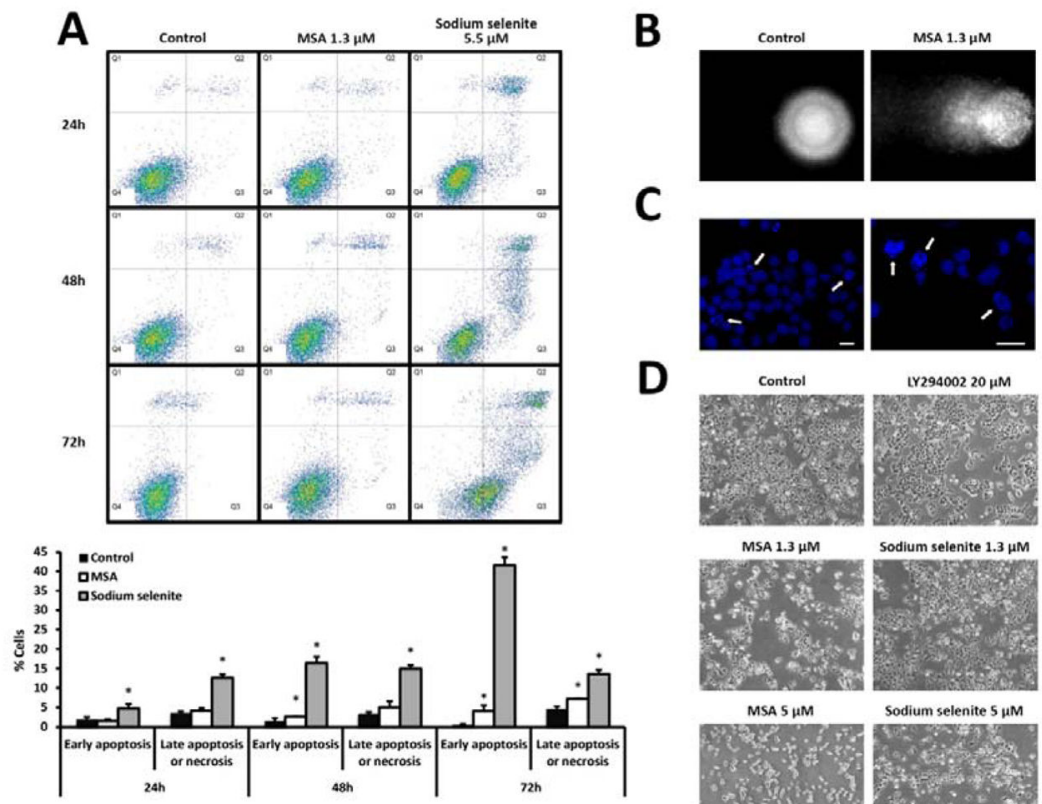

C

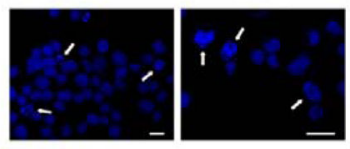

D
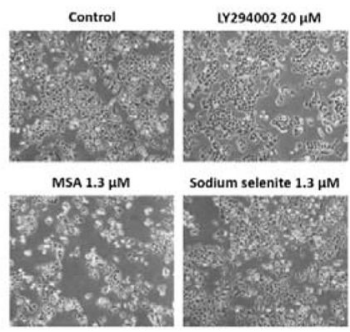

MSA S $\mu \mathrm{M}$

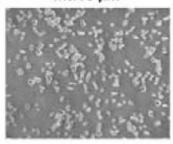

Sodium selenite 5 um
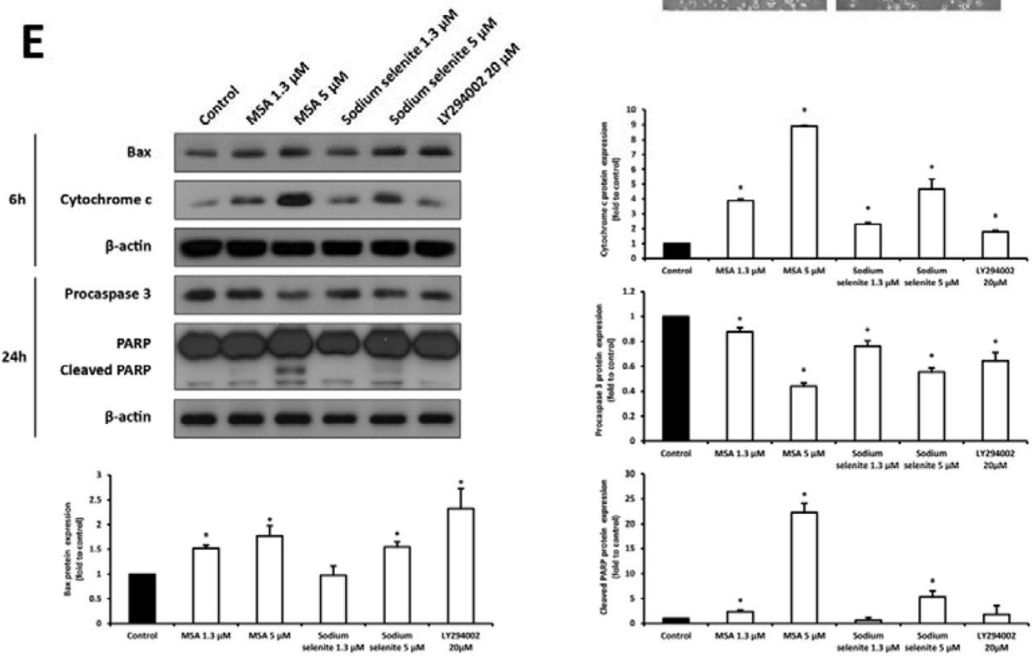

Figure 2. Apoptosis assays in A549 cells

A. Flow cytometry analysis of Annexin V-FITC staining and propidium iodide accumulation after exposure of A549 cells to MSA and sodium selenite at their respective ${ }^{72} \mathrm{IC}_{50}$ concentrations for 24, 48 and 72 hours. PI staining at $488 \mathrm{~nm}$ is represented on the $y$ axis and annexin V-FITC staining at $488 \mathrm{~nm}$ on the $x$ axis. Quadrant $4\left(\mathrm{PI}^{-} / \mathrm{FITC}^{-}\right)$represents non-apoptotic cells, early apoptosis is shown in right bottom quadrant $\left(\mathrm{PI}^{-} / \mathrm{FITC}^{+}\right)$and quadrants 1 and $2\left(\mathrm{PI}^{+}\right)$depict late apoptotic/necrotic cells. Plots illustrate the percentage of cells in early apoptosis and late apoptosis/necrosis. Values are expressed as mean \pm SD of three experiments in triplicate. Differences between treated and control groups were considered statistically significant at $\mathrm{p}<0.05(*)$. B. DAPI staining of A549 cells DNA after electrophoresis in agarose gel (single-cell gel electrophoresis, Comet Assay). Control condition treatment with vehicle showed no induction of single strand breaks while $24 \mathrm{~h}$ MSA exposure at ${ }^{72 \mathrm{~h}} \mathrm{IC}_{50}$ concentration caused DNA fragmentation in A549 cells. C. 
Morphological changes in nuclei were examined after $72 \mathrm{~h}$ MSA treatment at ${ }^{72} \mathrm{~h}_{\mathrm{IC}} \mathrm{C}_{50}$ concentration. Hoechst stained nuclei were evaluated with a fluorescence microscope (200 and $400 \mathrm{X}$, scale bar $3 \mu \mathrm{m}$ ) to detect increased condensation and margination of chromatin to the nuclear envelope and the formation of apoptotic bodies (white arrows). Apoptotic bodies were not observed in control condition. D. Cells were incubated with MSA, sodium selenite and LY294002 at the indicated concentrations for $24 \mathrm{~h}$ and observed using an inverted phase contrast microscope. E. Western blot analysis of total protein fractions of A549 cells. Protein expression was determined by densitometry analysis using ImageJ software and is represented as mean band intensity normalised to $\beta$-actin and related to untreated controls. MSA apoptosis activation is represented by enhancement of Bax and cytosolic cytochrome $\mathrm{c}$ expression, decrease of procaspase 3 levels and PARP cleavage $(*, p<0.05)$. Sodium selenite induced changes in the same direction but to a significantly lower extent. 
A

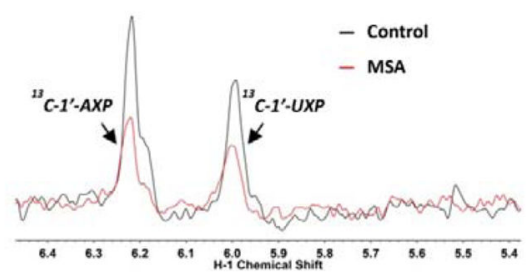

B

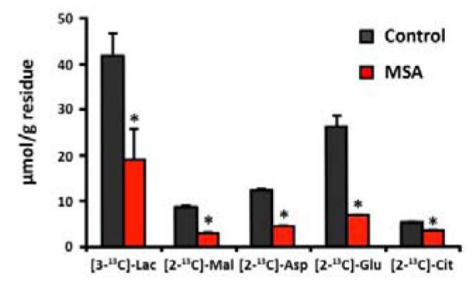

Figure 3. MSA perturbs glycolysis, TCA cycle and nucleotide biosynthesis

A549 cells were grown in $0.2 \%$ [U- $\left.{ }^{13} \mathrm{C}\right]$-glucose in the presence or absence of $5 \mu \mathrm{M}$ MSA for $24 \mathrm{~h}$. The polar metabolites were extracted in ice-cold $10 \%$ trichloroacetic acid and analysed by 1D HSQC NMR (A, acquired at $14.1 \mathrm{~T}, 20^{\circ} \mathrm{C}$ ) and GC-MS (B). A.

Representative 1D HSQC NMR spectrum. The abundance of the ribosyl unit of adenine $\left({ }^{13} \mathrm{C}-1^{\prime}-\mathrm{AXP}\right)$ and uracil $\left({ }^{13} \mathrm{C}-1^{\prime}-\mathrm{UXP}\right)$ nucleotides was significantly attenuated $24 \mathrm{~h}$ after MSA treatment, relative to the control treatment. B. The GC-MS analysis revealed reduced synthesis of TCA cycle metabolites, $\left[2-{ }^{13} \mathrm{C}\right]$-malate (Mal), $\left[2-{ }^{13} \mathrm{C}\right]$-aspartate (Asp), $\left[2-{ }^{13} \mathrm{C}\right]-$ glutamate $(\mathrm{Glu})$ and $\left[2-{ }^{13} \mathrm{C}\right]$-citrate $(\mathrm{Cit})$, in addition to the glycolytic product, $\left[3-{ }^{13} \mathrm{C}\right]-$ lactate $(\mathrm{Lac})$. $\mathrm{p}$ values $<0.05(*)$ were considered statistically significant. 
A

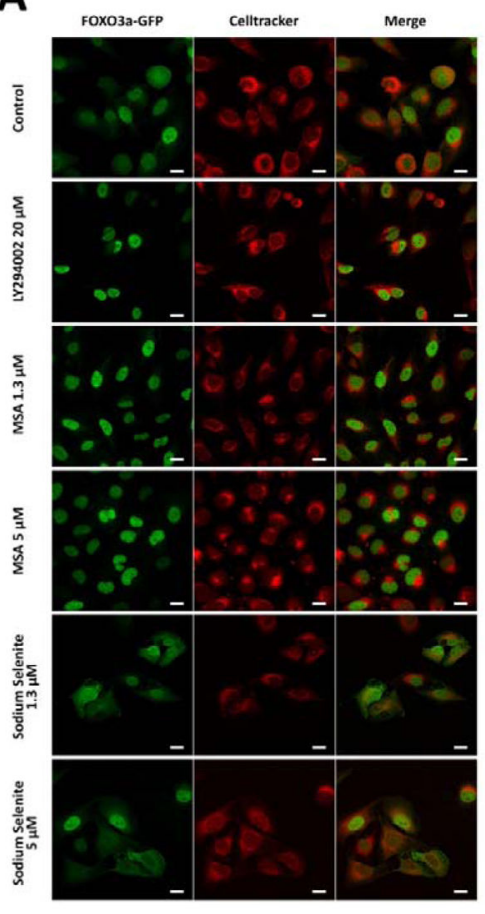

B
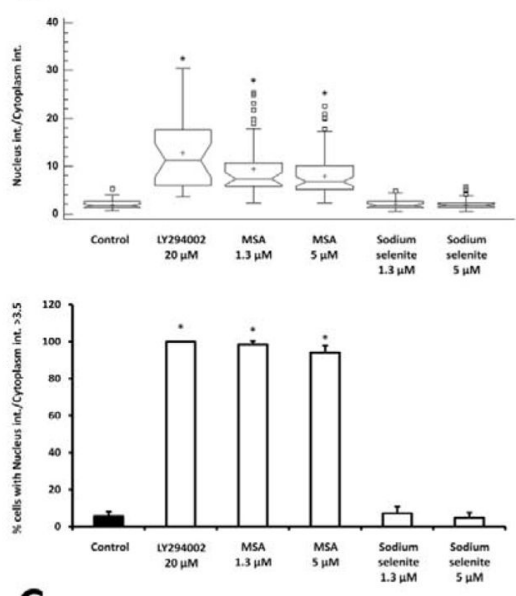

C

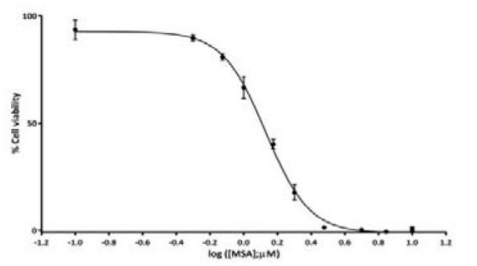

Figure 4. Nuclear translocation of GFP-FOXO following MSA treatment in U2foxRELOC cells U2foxRELOC cells stably expressing GFP-FOXO fusion protein were treated with vehicle, LY294002 (PI3K pathway inhibitor), MSA or sodium selenite for 6 hours. A. Representative confocal microscopy images for U2foxRELOC cells. Left row (green) indicates the subcellular location of FOXO3a-GFP. Celltracker location (red) identifies the cytoplasm. Scale bar, $5 \mu \mathrm{m}$. B. Box and whiskers plot for the correlation between the nuclear and cytoplasmic green fluorescence intensity. Higher values represent a higher FOXO3a-GFP presence in the nucleus compared to the cytoplasm. Bar graph shows the percentage of the cells in each condition exhibiting nuclear/cytoplasmic ratios of fluorescence intensity greater than 3.5. MSA and LY294002 treatments display statistically significant differences $(*)$ with the control condition using a multiple rang test (Kruskal-Wallis test) with $99 \%$ confidence. C. Viability assay with MSA in U2foxRELOC cells at $72 \mathrm{~h}$. Exponentially growing cells were treated with the indicated concentration of MSA for $72 \mathrm{~h}$. The assay was carried out using six replicates and repeated three times. Data are represented as mean $\pm \mathrm{SD}$. 


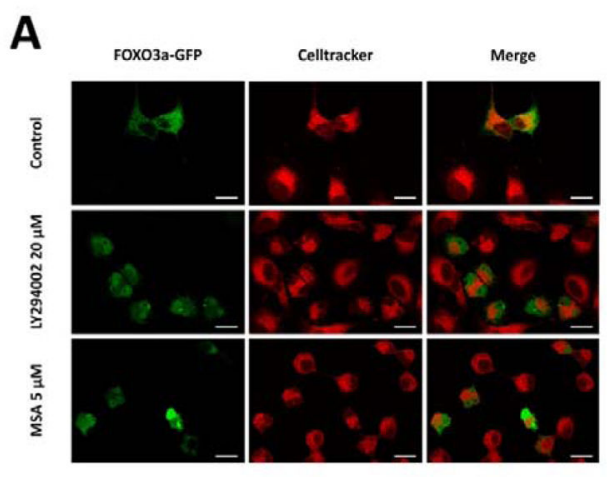

B

C

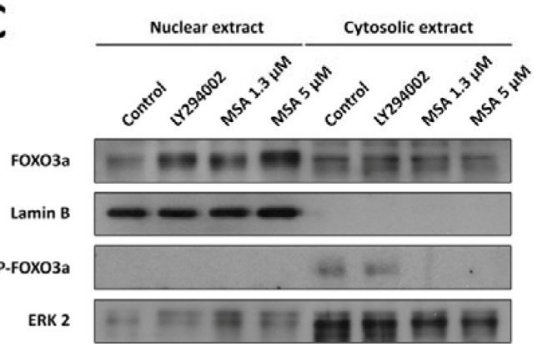

D
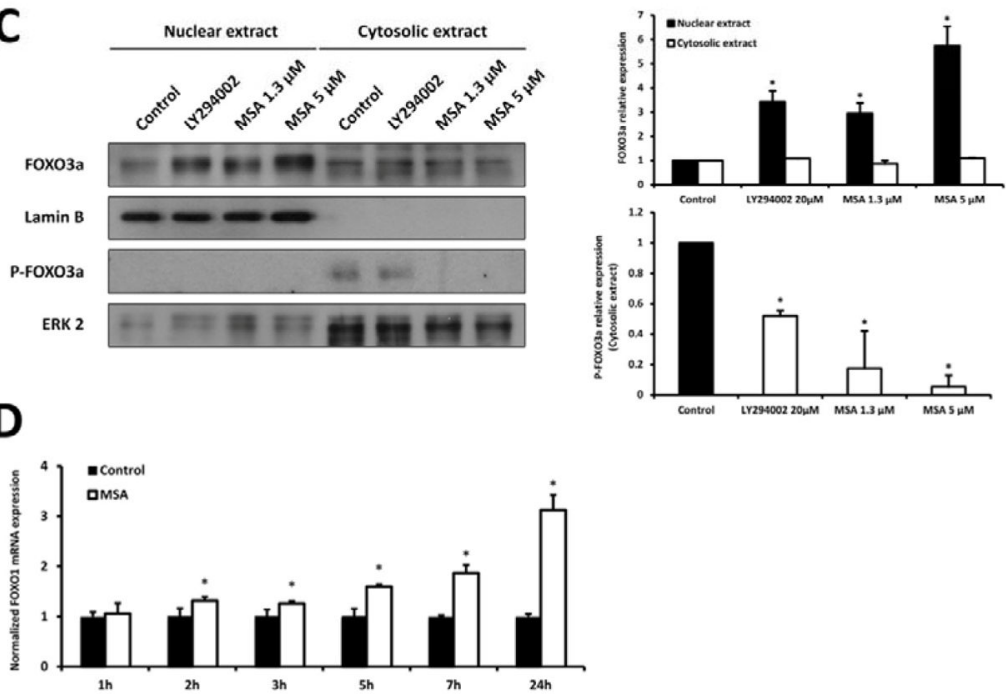

Figure 5. MSA induces GFP-FOXO3a nuclear translocation and increases endogenous nuclear FOXO3a in A549 cells

A. Representative confocal microscopy images for A549 cells transfected with a FOXO3aGFP reporter plasmid and treated with vehicle, $20 \mu \mathrm{M}$ LY294002 or $5 \mu \mathrm{M}$ MSA for $6 \mathrm{~h}$. Left row (green) indicates the intracellular location of FOXO3a-GFP. Celltracker location (red) identifies the cytoplasm. Scale bar, $5 \mu \mathrm{m}$. B. Box and whiskers plot for the correlation between the nuclear and cytoplasmic green fluorescence intensity. Higher values indicate a higher FOXO3a-GFP presence in the nucleus compared to the cytoplasm. Bar graph represents the percentage of the cells in each condition displaying nuclear/cytoplasmic ratios of fluorescence intensity greater than 1.5. MSA and LY294002 treatments present statistically significant differences $(*)$ with the control condition using a multiple rang test (Kruskal-Wallis test) with 99\% confidence. C. Western blots for the nuclear and cytoplasmic fractions of A549 cells. Protein expression levels were quantified using ImageJ software and are expressed as mean band intensity normalised to Lamin B (nuclear extract) or ERK 2 (cytosolic extract) and related to untreated controls. Endogenous nuclear FOXO3a levels increase with $6 \mathrm{~h}$ MSA and LY294002 treatments whereas phosphorylated FOXO3a cytoplasmic levels decrease $(*, p<0.05)$. D. mRNA levels of FOXO1 were analysed by qRT-PCR. Cells were incubated with $5 \mu \mathrm{M}$ MSA from $1 \mathrm{~h}$ up to $24 \mathrm{~h}$. The graph bar represents the expression of FOXO1 relative to control, which was assigned a value of 1. 
FOXO1 expression was significantly $(*, \mathrm{p}<0.05)$ and progressively induced from $2 \mathrm{~h}$ to 24

h. 

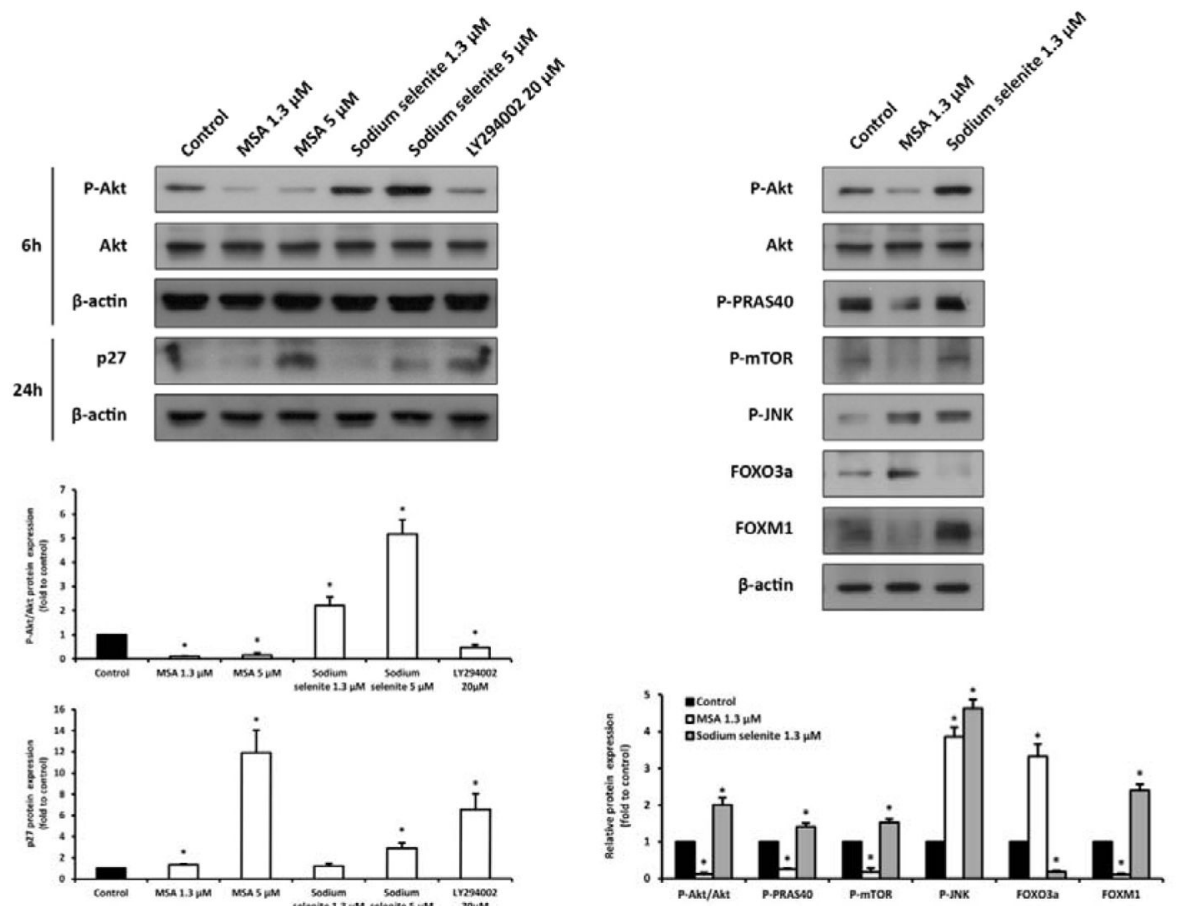

Figure 6. MSA-induced G1 arrest and apoptosis are associated with Akt inhibition Total protein fractions of A549 cells were analysed by Western blot. Protein expression was quantified by densitometric analysis using ImageJ software and is represented as mean band intensity normalised to $\beta$-actin and related to untreated controls. MSA induces the dephosphorylation of mTOR and Akt and its downstream target PRAS-40, the phosphorylation of JNK, an increase of FOXO3a levels, a reduction of FOXM1 protein expression and a G1 arrest represented by p27 accumulation. Differences between treated and control groups were considered statistically significant at $\mathrm{p}<0.05(*)$. 


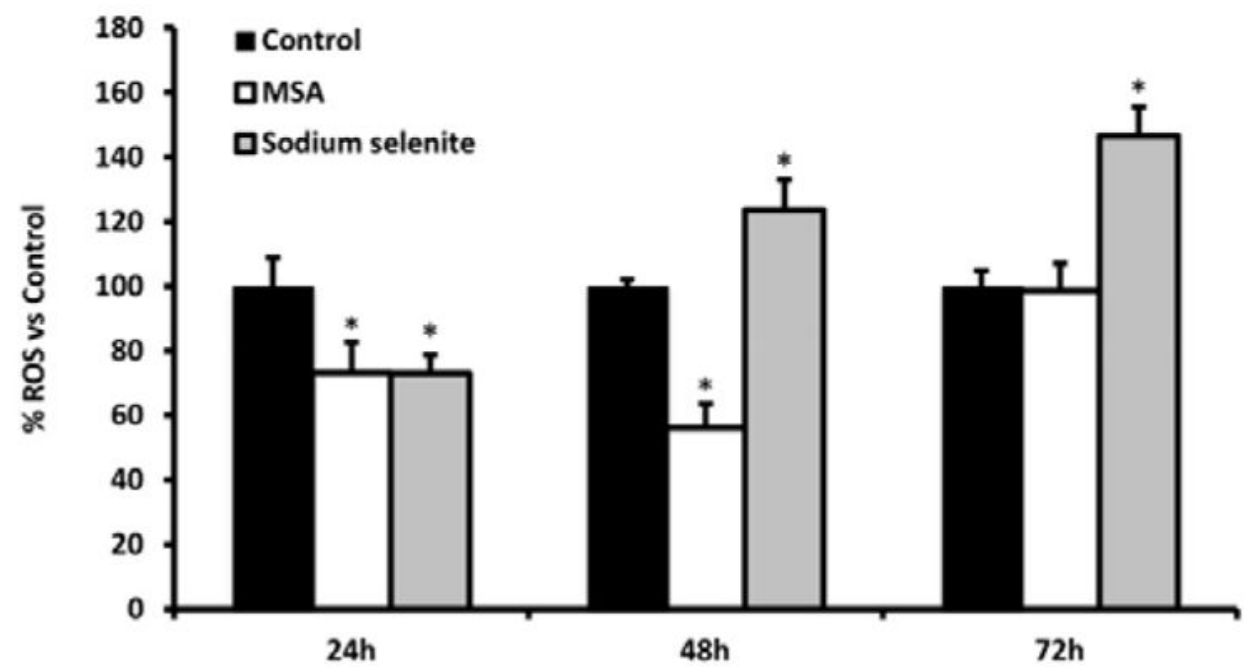

Figure 7. ROS detoxification by MSA treatment

A decrease in ROS levels was observed in MSA-treated A549 cells. This reduction was only statistically significant after 24 and $48 \mathrm{~h}\left(^{*}, \mathrm{p}<0.05\right)$. Cells treated with sodium selenite for $24 \mathrm{~h}$ presented similar ROS level to MSA-treated cells but significantly enhanced the production of ROS in a time-dependent manner after 48 and $72 \mathrm{~h}$ incubations. 

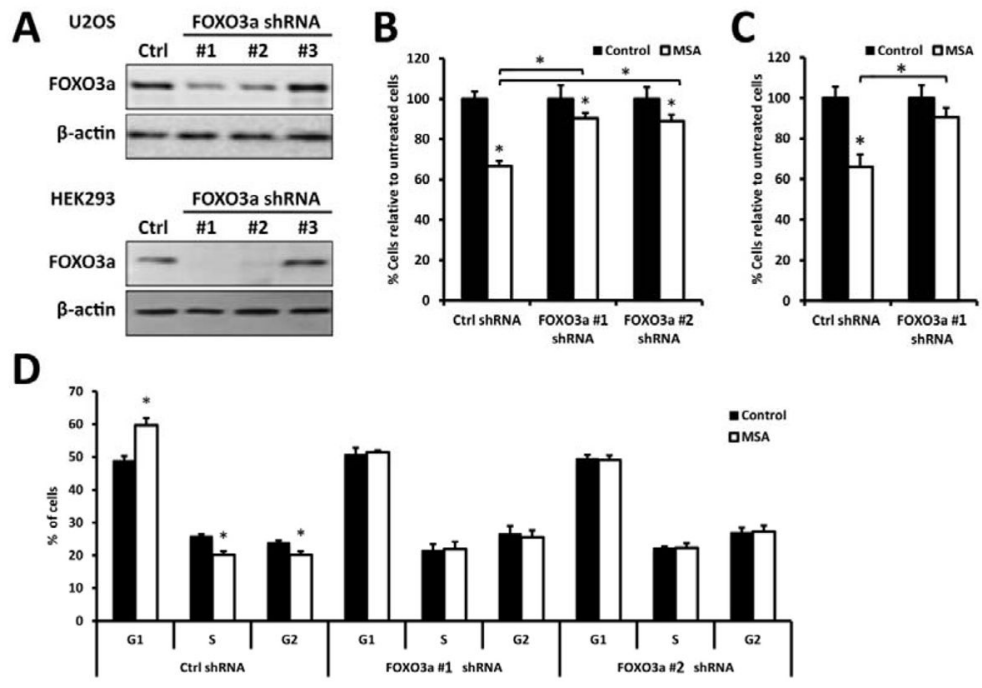

E

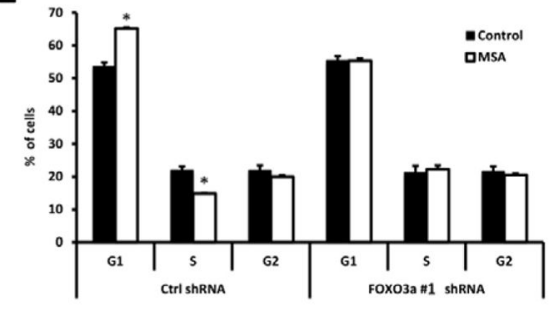

G

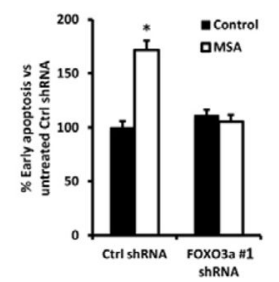

H

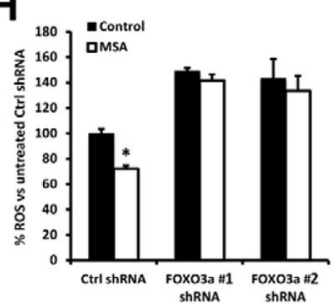

$\mathbf{F}$

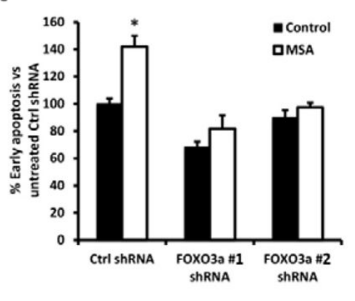

I

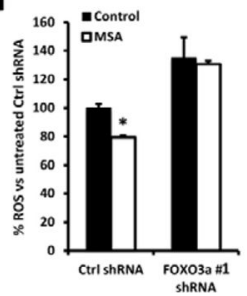

Figure 8. Effects of FOXO3a knockdown on MSA activity

U2OS and HEK293 cells were stably transfected with control shRNA (Ctrl) or constructs expressing two different FOXO3a-specific shRNA sequences (FOXO3a \#1 and FOXO3a \#2). A. Western blot analysis of total protein fractions of U2OS and HEK293 cells. $\beta$-actin was used as a protein loading control. Sequence \#1 exhibited the highest knockdown efficiency. B and C. Viability assays after treatment with $1 \mu \mathrm{M}$ MSA for $72 \mathrm{~h}$ in B. U2OS shRNA transfected cells and C. HEK293 shRNA transfected cells. Data are expressed as percentage of viability relative to untreated cells. D and E. Cell cycle analysis of $1 \mu \mathrm{M}$ MSA-treated cells for $72 \mathrm{~h}$ in D. U2OS shRNA transfected cells and E. HEK293 shRNA transfected cells. Cell cycle analysis was conducted after propidium iodide staining. F and G. Percentage of early apoptotic cells relative to untreated Ctrl shRNA cells obtained by flow cytometry analysis of Annexin V-FITC staining and propidium iodide accumulation after exposure of F. U2OS shRNA transfected cells and G. HEK293 shRNA transfected cells to $1 \mu \mathrm{M}$ MSA for $72 \mathrm{~h}$. $\mathbf{H}$ and I. Intracellular ROS levels determined by flow cytometry after 
$1 \mu \mathrm{M}$ MSA incubation for $48 \mathrm{~h}$ of $\mathbf{H}$. U2OS shRNA transfected cells and I. HEK293 shRNA transfected cells. Results are expressed as percentage of mean fluorescent intensity relative to untreated Ctrl shRNA cells. In all cases, values represent mean \pm SD and statistically significant differences between treated and control cells at $\mathrm{p}<0.05$ are indicated with an asterisk (*). 

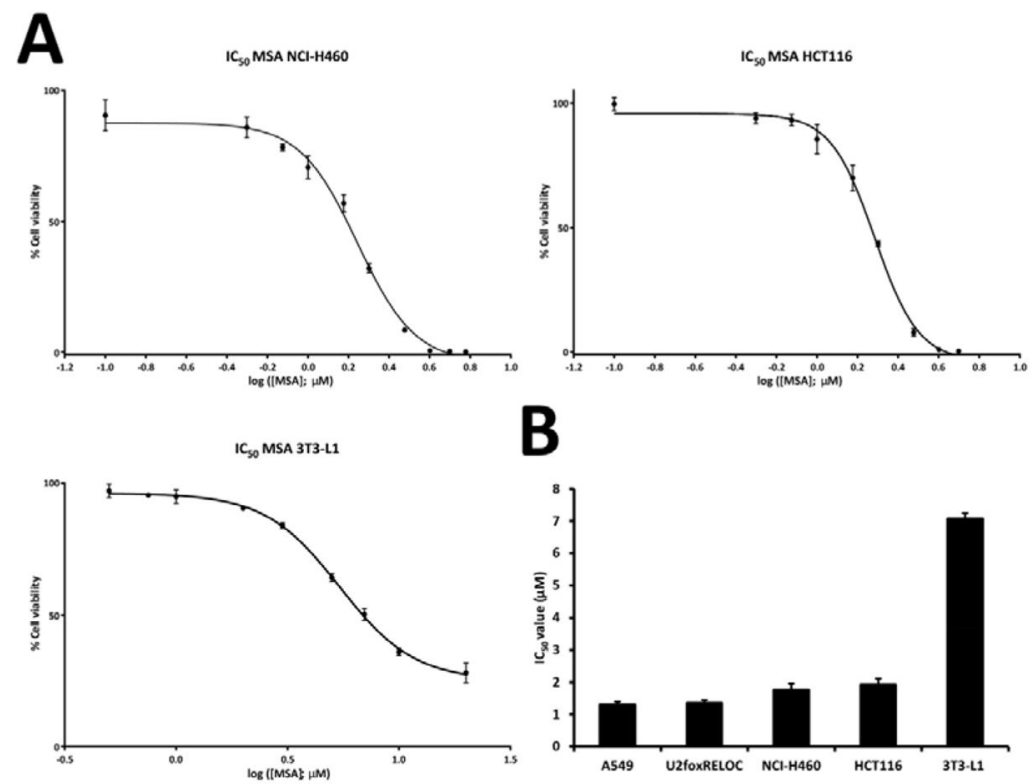

Figure 9. Effect of MSA on cell viability

A. Viability assays with MSA in NCI-H460, HCT116 and differentiated 3T3-L1 cells. B. Comparison between the ${ }^{72 \mathrm{~h}} \mathrm{IC}_{50}$ values for the tested cell lines. The MSA concentration that caused $50 \%$ of inhibition of cell viability at $72 \mathrm{~h}$ of treatment for the 3T3-L1 non-tumour cell line was three to five times the value for all tumour cell lines analysed. 


\section{Table 1}

\section{Synergistic antiproliferative effect of MSA and cisplatin combination treatment}

Cells were treated for $72 \mathrm{~h}$ at the indicated concentrations of MSA and cisplatin in a constant ratio. A. A549 cells, ratio 1:10. B. HCT116 cells, ratio 1:5. C. MCF7 cells, ratio 1:4. D. OVCAR3 cells, ratio 1:5. The CI results obtained with CompuSyn software revealed a synergy $(\mathrm{CI}<1)$ in the antiproliferative effects of MSA and cisplatin at each dose combination tested.

\begin{tabular}{llll}
\multicolumn{5}{l}{ A. A549 cells, ratio 1:10. } \\
\hline MSA $(\boldsymbol{\mu M})$ & Cisplatin $(\boldsymbol{\mu M})$ & Viability $(\%)$ & CI Value \\
\hline 0.05 & 0.5 & $91.1 \pm 1.8$ & 0.570 \\
0.1 & 1 & $78.9 \pm 1.1$ & 0.447 \\
0.3 & 3 & $56.5 \pm 2.0$ & 0.631 \\
0.5 & 5 & $41.1 \pm 3.4$ & 0.707 \\
0.75 & 7.5 & $27.9 \pm 2.6$ & 0.751 \\
1 & 10 & $17.3 \pm 0.5$ & 0.729 \\
1.3 & 13 & $8.5 \pm 0.5$ & 0.663 \\
1.5 & 15 & $4.2 \pm 0.5$ & 0.578 \\
2 & 20 & $1.8 \pm 0.5$ & 0.595 \\
\hline
\end{tabular}

\section{B. HCT116 cells, ratio 1:5.}

\begin{tabular}{llll} 
MSA $(\boldsymbol{\mu M})$ & Cisplatin $(\boldsymbol{\mu M})$ & Viability $(\%)$ & CI Value \\
\hline 0.75 & 3.75 & $74.5 \pm 4.9$ & 0.717 \\
1 & 5 & $62.8 \pm 3.9$ & 0.667 \\
1.5 & 7.5 & $45.1 \pm 3.0$ & 0.669 \\
2 & 10 & $34.9 \pm 3.9$ & 0.725 \\
2.5 & 12.5 & $26.0 \pm 2.4$ & 0.750 \\
3 & 15 & $16.8 \pm 2.1$ & 0.716 \\
3.5 & 17.5 & $11.0 \pm 1.3$ & 0.695 \\
4 & 20 & $3.6 \pm 0.7$ & 0.517 \\
5 & 25 & $2.6 \pm 0.6$ & 0.579 \\
\hline
\end{tabular}

C. MCF7 cells, ratio 1:4.

\begin{tabular}{llll} 
MSA $(\boldsymbol{\mu M})$ & Cisplatin $(\boldsymbol{\mu M})$ & Viability $(\%)$ & CI Value \\
\hline 0.5 & 2 & $78.0 \pm 1.2$ & 0.275 \\
0.75 & 3 & $74.6 \pm 2.3$ & 0.363 \\
1 & 4 & $74.1 \pm 2.1$ & 0.476 \\
1.5 & 6 & $70.2 \pm 0.5$ & 0.629 \\
2 & 8 & $66.6 \pm 0.1$ & 0.753 \\
2.5 & 10 & $49.5 \pm 2.3$ & 0.608 \\
3 & 12 & $39.5 \pm 3.2$ & 0.575 \\
3.5 & 14 & $19.9 \pm 2.1$ & 0.392 \\
4 & 16 & $13.5 \pm 1.4$ & 0.350 \\
\hline
\end{tabular}


D. OVCAR3 cells, ratio 1:5.

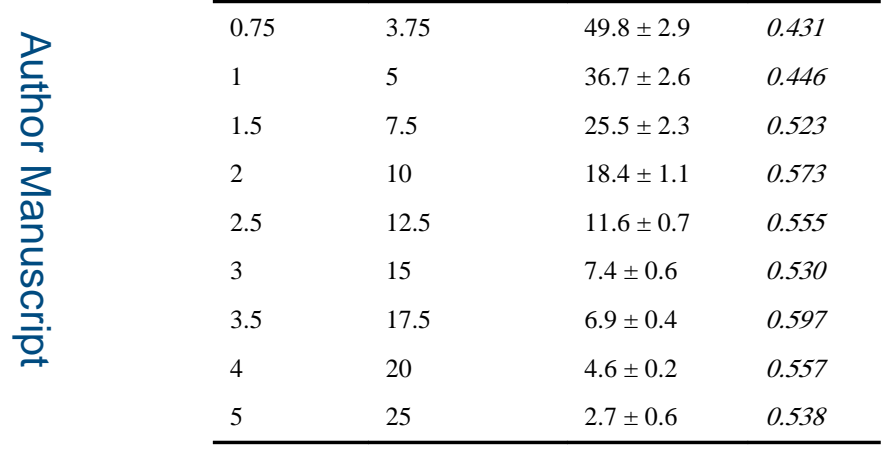

를

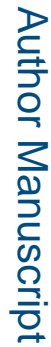

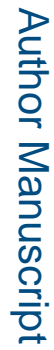

Pharmacol Res. Author manuscript; available in PMC 2016 April 28. 


\section{Table 2}

Synergistic antiproliferative effect of MSA and carboplatin combination treatment.Cells were treated for $72 \mathrm{~h}$ at the indicated concentrations of MSA and carboplatin in a constant ratio. A. A549 cells, ratio 1:6. B. HCT116 cells, ratio 1:10. C. MCF7 cells, ratio 1:6. D. OVCAR3 cells, ratio 1:6. The CI results obtained with CompuSyn software revealed a synergistic $(\mathrm{CI}<1)$ antiproliferative effect of MSA and carboplatin at each dose combination tested.

\begin{tabular}{llll}
\multicolumn{5}{l}{ A. A549 cells, ratio 1:6. } \\
MSA $(\boldsymbol{\mu M})$ & Cisplatin $(\boldsymbol{\mu M})$ & Viability $(\%)$ & CI Value \\
\hline 0.5 & 3 & $81.2 \pm 4.1$ & 0.408 \\
0.75 & 4.5 & $71.3 \pm 5.2$ & 0.642 \\
1 & 6 & $61.2 \pm 0.4$ & 0.637 \\
1.5 & 9 & $48.2 \pm 1.4$ & 0.775 \\
2 & 12 & $30.7 \pm 3.2$ & 0.781 \\
2.5 & 15 & $19.3 \pm 0.9$ & 0.626 \\
3 & 18 & $12.8 \pm 2.1$ & 0.792 \\
3.5 & 21 & $10.5 \pm 1.3$ & 0.816 \\
4 & 24 & $8.1 \pm 0.5$ & 0.887 \\
\hline
\end{tabular}

\section{B. HCT116 cells, ratio 1:10.}

\begin{tabular}{llll} 
MSA $(\boldsymbol{\mu M})$ & Cisplatin $(\boldsymbol{\mu M})$ & Viability $(\%)$ & CI Value \\
\hline 0.25 & 2.5 & $89 \pm 1.3$ & 0.306 \\
0.5 & 5 & $77 \pm 1.9$ & 0.398 \\
1 & 10 & $72 \pm 0.2$ & 0.661 \\
1.5 & 15 & $55 \pm 0.6$ & 0.731 \\
2 & 20 & $38 \pm 3.4$ & 0.711 \\
2.5 & 25 & $22 \pm 2.0$ & 0.674 \\
3 & 30 & $14 \pm 0.6$ & 0.692 \\
3.5 & 35 & $12 \pm 1.5$ & 0.752 \\
4 & 40 & $4 \pm 2.8$ & 0.608 \\
5 & 50 & $2 \pm 0.6$ & 0.567 \\
\hline
\end{tabular}

C. MCF7 cells, ratio 1:6.

\begin{tabular}{llll}
\hline MSA $(\boldsymbol{\mu M})$ & Cisplatin $(\boldsymbol{\mu M})$ & Viability $(\%)$ & CI Value \\
\hline 0.5 & 3 & $84.9 \pm 5.4$ & 0.295 \\
0.75 & 4.5 & $70.3 \pm 3.9$ & 0.299 \\
1 & 6 & $63.5 \pm 5.0$ & 0.347 \\
1.5 & 9 & $55.2 \pm 2.0$ & 0.445 \\
2 & 12 & $46.7 \pm 4.3$ & 0.510 \\
2.5 & 15 & $36.1 \pm 5.0$ & 0.523 \\
3 & 18 & $15.8 \pm 4.2$ & 0.381 \\
3.5 & 21 & $13.4 \pm 1.3$ & 0.408 \\
4 & 24 & $11.2 \pm 0.7$ & 0.424 \\
5 & 30 & $8.7 \pm 0.7$ & 0.469 \\
\hline
\end{tabular}




\begin{tabular}{|c|c|c|c|c|}
\hline \multirow{9}{*}{ 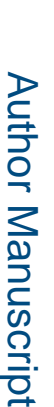 } & MSA $(\mu \mathrm{M})$ & Cisplatin $(\mu \mathrm{M})$ & Viability (\%) & CI Value \\
\hline & 0.75 & 4.5 & $85.1 \pm 1.8$ & 0.668 \\
\hline & 1 & 6 & $77.5 \pm 5.1$ & 0.697 \\
\hline & 1.5 & 9 & $66.9 \pm 0.5$ & 0.908 \\
\hline & 2 & 12 & $44.4 \pm 0.0$ & 0.862 \\
\hline & 2.5 & 15 & $37.1 \pm 1.0$ & 0.966 \\
\hline & 3 & 18 & $24.7 \pm 0.6$ & 0.937 \\
\hline & 3.5 & 21 & $14.9 \pm 0.1$ & 0.874 \\
\hline & 4 & 24 & $6.5 \pm 2.0$ & 0.719 \\
\hline & 5 & 30 & $3.2 \pm 0.6$ & 0.686 \\
\hline
\end{tabular}

D. OVCAR3 cells, ratio 1:6.

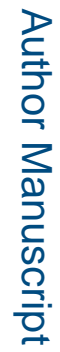

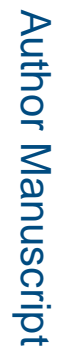

Pharmacol Res. Author manuscript; available in PMC 2016 April 28. 